\title{
Successes and failures of Hubbard-corrected density functional theory: The case of $\mathrm{Mg}$ doped $\mathrm{LiCoO}_{2}$
}

\author{
Juan A. Santana, ${ }^{1}$ Jeongnim Kim, ${ }^{1}$ P. R. C. Kent, ${ }^{2,3}$ and Fernando A. Reboredo, 国 \\ ${ }^{1)}$ Materials Science and Technology Division, Oak Ridge National Laboratory, Oak Ridge, TN 37831, \\ USA \\ ${ }^{2)}$ Center for Nanophase Materials Sciences, Oak Ridge National Laboratory, Oak Ridge, TN 37831, \\ USA \\ ${ }^{3)}$ Computer Science and Mathematics Division, Oak Ridge National Laboratory, Oak Ridge, TN 37831, \\ $U S A$
}

(Dated: 5 July 2021)

\begin{abstract}
We have evaluated the successes and failures of the Hubbard-corrected density functional theory (DFT+U) approach to study $\mathrm{Mg}$ doping of $\mathrm{LiCoO}_{2}$. We computed the effect of the $\mathrm{U}$ parameter on the energetic, geometric and electronic properties of two possible doping mechanisms: (1) substitution of Mg onto a Co (or $\mathrm{Li}$ ) site with an associated impurity state and, (2) formation of impurity-state-free complexes of substitutional $\mathrm{Mg}$ and point defects in $\mathrm{LiCoO}_{2}$. We find that formation of impurity states results in changes on the valency of $\mathrm{Co}$ in $\mathrm{LiCoO}_{2}$. Variation of the $\mathrm{Co} \mathrm{U}$ shifts the energy of the impurity state, resulting in energetic, geometric and electronic properties that depend significantly on the specific value of $U$. In contrast, the properties of the impurity-state-free complexes are insensitive to $U$. These results identify reasons for the strong dependence on the doping properties on the chosen value of $U$ and for the overall difficulty of achieving agreement with the experimentally known energetic and electronic properties of doped transition metal oxides such as $\mathrm{LiCoO}_{2}$.
\end{abstract}

\section{INTRODUCTION}

Although theory has been used to support research in new rechargeable battery materials, $\frac{1}{,}$ whether theory can be used to design new materials without experimental input will largely depend on the ability of electronic structure methods to describe new and existing materials with accuracies compatible with experimental needs. ${ }^{2}-4$ Thus, in order to respond to initiatives such as the Materials Genome,,$\frac{5}{5}$ the predictive power of theory must be characterized.

In energy storage research, a significant challenge is to accurately predict the thermodynamic phase stability and ionic/electronic conductivity of cathode materials $, 1,6$ This is because theoretical calculations are mainly based on Density Functional Theory (DFT) within the local density (LDA) and generalized gradient (GGA) approximations. While these approximations are accurate enough to study the thermodynamic and conductive properties of many materials, they are unreliable in others, e.g., transition metal-oxides. Approximations such as LDA and GGA do not account properly for exchange and correlation effects in transition metal-oxides, leading to exchange-correlation errors such as the selfinteraction error $\stackrel{9}{\underline{9}}$ In practice a semi-empirical approach is adopted in an attempt to minimize these errors, but the use of experimental data for the calibration and validation inevitably reduces the predictive power of the method.

The doping of cathode materials is an example where it is crucial to accurately predict thermodynamic and

a) Electronic mail: reboredofa@ornl.gov conductive properties and where a predictive theory is highly desired. A case that exemplifies the problem is the doping of $\mathrm{LiCoO}_{2}$ with cations such as $\mathrm{Mg}$. The effect of $\mathrm{Mg}$-doping on the electronic conductivity and longterm capacity retention of layered $\mathrm{LiCoO}_{2}$-based batteries have been extensively studied. ${ }^{10-33}$ Carewska et al. 10 and Tukamoto and West ${ }^{11}$ showed that doping $\mathrm{LiCoO}_{2}$ with $\mathrm{Mg}$ increases its electronic conductivity. This higher conductivity was rationalized by considering the generation of electronic holes due to the formation of a mixed $+3 /+4$ valence state in Co ${ }^{10,11}$ Later studies ${ }^{17,18,34-36}$ supported this model and suggested that the transfer of an electron from $\mathrm{Co}$ ion to $\mathrm{O} 2 p$ hole is also involved in raising the conductivity. The formation of oxygen vacancies in $\mathrm{Mg}$-doped $\mathrm{LiCoO}_{2}$ has also been proposed to contribute to the higher conductivity, $\underline{15,16,30}$

In addition to the increased conductivity, a significant capacity retention for $\mathrm{Mg}$-doped $\mathrm{LiNiCoO}_{2}$-based batteries was independently reported by Chang et al., 37 Cho 38 and Kweon et al. ${ }^{39}$ For example, Cho found $92 \%$ capacity retention for $\mathrm{LiNi}_{0.74} \mathrm{Co}_{0.22} \mathrm{Mg}_{0.04} \mathrm{O}_{2}$ after $94 \mathrm{cy}$ cles at $1 \mathrm{C}$ rate vs. $70 \%$ for $\mathrm{LiNi}_{0.74} \mathrm{Co}_{0.26} \mathrm{O}_{2}{ }^{38} \mathrm{Mg}$ doping also improves the thermal stability of Li-ion batteries. Similar improved capacity and thermal properties were later reported by other authors for $\mathrm{LiCoO}_{2}$-based batteries ${ }^{12-15,17-33}$ However, doping $\mathrm{LiCoO}_{2}$ and $\mathrm{LiNiO}_{2}$ based cathode materials with $\mathrm{Mg}$ cations has the drawback of decreasing the capacity ${ }^{11,13,37-39}$ because $\mathrm{Mg}$ reduces the concentration of the active $\mathrm{Ni}^{3+}$ or $\mathrm{Co}^{3+}$ ion sites $11,37,38$

Several explanations for the stability of Mg-doped Li-ion batteries have been proposed. Cho proposed that a lower cation mixing in $\mathrm{LiNi}_{0.74} \mathrm{Co}_{0.26-x} \mathrm{Mg}_{x} \mathrm{O}_{2}$ than in $\mathrm{LiNi}_{0.74} \mathrm{Co}_{0.26} \mathrm{O}_{2}$ battery leads to the improved stability $\stackrel{38}{=}$ A large degree of cation mixing, where Li ions 
partially occupy the $\mathrm{Ni}(\mathrm{Co})$ sites and vise versa, results in lower capacity and affects the structural stability of the layered material $\stackrel{38.40}{ }$

The higher stability has also been rationalized as a pillaring effect, where $\mathrm{Mg}$ located in the oxide layers or inter-layer spaces prevents the structural collapse and crystallinity loss during charge/discharge. However, it is still unclear if $\mathrm{Mg}$ is located in oxide layers or interlayers spaces, i.e. whether $\mathrm{Mg}$ is on $\mathrm{Li}$ or transition metal sites. It has been proposed that $\mathrm{Mg}$ is initially on the transition metal sites, but it migrates to the inter-layer spaces after initial cycling, $\stackrel{22,41-43}{\underline{4}}$ Xiang et al $\stackrel{44}{\underline{4}}$ proposed a similar model based on a detailed analysis of measured change in the volume of $\mathrm{LiNi}_{0.80-x} \mathrm{Co}_{0.20} \mathrm{Mg}_{x} \mathrm{O}_{2}$ as function of $x$ and possible substitutions and charge balance mechanisms for Mg. They suggested that the stronger $\mathrm{Mg}-\mathrm{O}$ bond (vs. Li-O) enhances the stability of $\mathrm{LiNi}_{1-x} \mathrm{Co}_{x} \mathrm{O}_{2}$-based batteries. On the other hand, Chang et al $\stackrel{37}{\underline{3}}$ found that $\mathrm{Mg}$ cations are mainly on $\mathrm{Ni}$ sites. They argued that $\mathrm{Mg}$ stabilizes the $\mathrm{NiO}_{2}$ slab, preventing thermal and cycling decomposition $\stackrel{37}{ }$ Tatsumi et $a l: \stackrel{45}{\underline{4}}$ also found $\mathrm{Mg}$ cations to preferentially replace $\mathrm{Ni}$ sites initially, but to diffuse out of the active material during cycling. More recently, Tavakoli et al $\stackrel{46}{\underline{4}}$ proposed that a short-range ordering of $\mathrm{Ni}$ cations around $\mathrm{Mg}$ results on $\mathrm{LiNi}_{0.755} \mathrm{Co}_{0.147} \mathrm{Al}_{0.045} \mathrm{Mg}_{0.053} \mathrm{O}_{2}$ batteries 34.2 $\pm 9.3 \mathrm{meV}$ more thermodynamically stable than undoped $\mathrm{LiNi}_{0.800} \mathrm{Co}_{0.155} \mathrm{Al}_{0.045} \mathrm{O}_{2}$. Such stabilization can provide stronger bonding and prevent the formation of NiO-like phase during charge/discharge $\underline{\underline{46}}$

Despite the significant experimental efforts outlined above, it is still unclear how Mg-doping improves the stability of $\mathrm{LiCoO}_{2}$ and $\mathrm{LiNiO}_{2}$ based batteries. In part, this is because no theoretical work has been performed to evaluate the thermodynamic profile of $\mathrm{Mg}$ in these batteries. Calculations have mainly focused on the electronic properties,,$\frac{18,34,35}{=}$ lattice stability $\underline{36}$ and Li-intercalation voltage $e^{36}$ of $\mathrm{Mg}$-doped $\mathrm{LiCoO}_{2}$. Calculations have also been employed to study the site preference of $\mathrm{Mg}$ in $\mathrm{LiNiO}_{2}$ by combining theory, x-ray absorption near-edge structure and electron energy-loss near-edge structure measurements $\underline{\underline{45}}$

The relative lack of calculations for the thermodynamics of $\mathrm{Mg}$ in these cathode materials comes because such calculations of impurities in transition metal-oxides are rather difficult within the framework of DFT. This is mainly because of DFT errors in transition metaloxides. These errors can be partially removed by introducing an on-site Hubbard model correction (DFT $+\mathrm{U}) \underline{\underline{47}}$ This method has been successfully used to study Liion battery cathodes $\stackrel{45,48-51}{\underline{4}}$ and other transition metaloxides $\underline{52-54}$ It is also the standard approach adopted by the "Materials Project" $\underline{54}$ for high throughput computation of materials, including metal-oxides. However, physically, the parameter U should depend on the chemical environment of the atomic site where it is applied, while in conventional $\mathrm{DFT}+\mathrm{U}$ calculations a universal value of $\mathrm{U}$ is used. As a result $\mathrm{DFT}+\mathrm{U}$ often fails to correctly predict the relative energy between systems with a mixture of localized and delocalized electronic states $\underline{53}$ This is particularly problematic if one uses $\mathrm{DFT}+\mathrm{U}$ to study dopants that can induce localized or delocalized states in transition metal-oxides.

$\mathrm{Mg}$ is a divalent dopant and its substitution onto a Co or Li site can induce a localized or delocalized state in $\mathrm{LiCoO}_{2}$. Therefore, to elucidate how $\mathrm{Mg}$ improves the performance of the $\mathrm{LiCoO}_{2}$ cathode material using $\mathrm{DFT} / \mathrm{DFT}+\mathrm{U}$ methods, a first step is to study how sensitive the calculated properties of $\mathrm{Mg}$-doped $\mathrm{LiCoO}_{2}$ are to different choices of the parameter $\mathrm{U}$. To this end, we studied the effect of $U$ on the energetic, geometric and electronic properties of $\mathrm{Mg}$ when it is located on Co and $\mathrm{Li}$ sites as well as when it forms complexes with $\mathrm{Li}$ vacancies or interstitial sites in $\mathrm{LiCoO}_{2}$.

The remainder of this article is organized as follows. We first discuss the doping mechanisms that were examined, the computational methods employed and how the chemical potentials were established. We then present our results. We start by analyzing the effect of the U parameter on the range of chemical potentials, emphasizing the effect on the phase boundaries of $\mathrm{LiCoO}_{2}$. Subsequently, we discuss the effect of $\mathrm{U}$ on the formation energy, geometry and electronic structure of Mg-doped $\mathrm{LiCoO}_{2}$. We conclude with a summary and our conclusions.

\section{METHODOLOGY}

\section{A. Substitutional $\mathrm{Mg}$ in $\mathrm{LiCoO}_{2}$}

$\mathrm{Mg}$ is formally a divalent dopant, $\mathrm{Mg}^{2+}$, and its substitution onto a Co or $\mathrm{Li}$ site in $\mathrm{LiCoO}_{2}$ is an aliovalent substitution that requires a mechanism for charge compensation. One possible mechanism is the formation of new electronic species. In this mechanism, the substitution of $\mathrm{Mg}^{2+}$ onto a $\mathrm{Co}^{3+}$ site leads to the extrinsic $\mathrm{Mg}_{\mathrm{Co}}$ defect and a concomitant increase in the oxidation state of a Co site from $3+$ to $4+$, which introduces an impurity hole in the system. This mechanism was originally proposed to rationalize the high conductivity of $\mathrm{Mg}$-doped $\mathrm{LiCoO}_{2}, \underline{10}, \underline{11}$ On the other hand, the substitution of $\mathrm{Mg}^{2+}$ onto a $\mathrm{Li}^{+}$site is balanced by the formation of a Co site with oxidation state +2 , i.e an impurity electron is introduced in the system.

Other mechanisms for charge compensation can involve the formation of vacancy, interstitial and anti-site

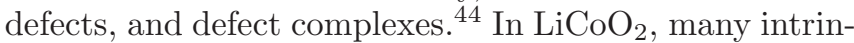
sic defects can combine with substitutional $\mathrm{Mg}$ and form a complex for charge compensation. $\mathrm{Mg}_{C o}$ can form a complex with electron donor defects such as $\mathrm{V}_{O}^{+}, \mathrm{Co}_{i}^{2+}$, $\mathrm{Li}_{i}$ and $\mathrm{Co}_{L i}^{+}$, while $\mathrm{Mg}_{L i}$ with electron acceptor defects such as $\mathrm{V}_{L i}, \mathrm{~V}_{C o}^{2-}, \mathrm{Li}_{C o}^{-}$. Recent calculations ${ }^{51,55}$ have shown that, of these ionic defects, the dominant one under typical synthesis conditions is the anti-site $\mathrm{Co}_{L i}^{+}$defect. The other intrinsic defects have high formation en- 
ergies and are expected to have a low concentration $\underline{\underline{51}}$ Based on such reports, we considered in our initial calculations the $\mathrm{Mg}_{C o}-\mathrm{Co}_{L i}^{+}$complex as a charge compensation mechanism. However, the formation energy of this complex is over $1.5 \mathrm{eV}$ when the system is under charge neutrality and, therefore, it was not further considered 56 Instead, we considered the neutral complexes $\mathrm{Mg}_{C o}-\mathrm{Li}_{i}$ and $\mathrm{Mg}_{L i}-\mathrm{V}_{L i}$ as they can be relevant to the electrochemistry of $\mathrm{Mg}$-doped $\mathrm{LiCoO}_{2}$. Additionally, we studied the charge compensation by the dual substitution of $\mathrm{Mg}$ on $\mathrm{Co}$ and $\mathrm{Li}$ sites, i.e. the $\mathrm{Mg}_{C o}-\mathrm{Mg}_{L i}$ complex.

To quantify the incorporation of $\mathrm{Mg}$ in $\mathrm{LiCoO}_{2}$, we evaluated the formation energy of the possible extrinsic defects and defect complexes as:

$$
E^{f}(X)=E_{t o t}[X]-E_{t o t}\left[L i C o O_{2}\right]-\sum_{i} n_{i} \mu_{i}
$$

where $X$ is a neutral extrinsic or intrinsic defect (or defect complex). $\mathrm{E}_{\text {tot }}[\mathrm{X}]$ and $\mathrm{E}_{\text {tot }}\left[\mathrm{LiCoO}_{2}\right]$ are the total energy of $\mathrm{LiCoO}_{2}$ containing $X$ and the total energy of the equivalent bulk $\mathrm{LiCoO}_{2}$, respectively. $n_{i}$ is the number of atomic species $i$ added $\left(n_{i}>0\right)$ or removed $\left(n_{i}<0\right)$ from the supercell, while $\mu_{i}$ indicates the corresponding atomic chemical potentials. The stability of the complexes is quantified by their binding energies as: $: 57$

$$
E_{b}=E^{f}(X)+E^{f}(Y)-E^{f}(X Y)
$$

where $\mathrm{E}^{f}(X Y), \mathrm{E}^{f}(X)$ and $\mathrm{E}^{f}(Y)$ are the formation energy of the complexes and those of the individual defects, respectively. In this notation, a positive binding energy indicates a bound complex.

\section{B. DFT Calculations}

The total energies to evaluate Eq. (1) were calculated within the DFT framework as implemented on the Vienna Ab-initio Software Package (VASP) $5 \underline{56}$ We used the Perdew-Burke-Ernzerhof (PBE) $)^{62,63}$ exchange and correlation functionals. The $\mathrm{Li}, \mathrm{O}, \mathrm{Mg}$ and $\mathrm{Co}$ ionic cores were represented by the projector augmented-wave (PAW) potentials $\frac{64.65}{6}$ with $3,6,8$ and 9 valence electrons, respectively. The wavefunction energy cutoff was set to $520 \mathrm{eV}$. We initialized the transition metal atoms in both high and low spin states with ferromagnetic ordering and the configuration with the lowest energy was used. The k-point mesh employed to calculate the bulk properties of $\mathrm{LiCoO}_{2}, \mathrm{CoO}, \mathrm{Co}_{3} \mathrm{O}_{4}, \mathrm{Li}_{6} \mathrm{CoO}_{4}, \mathrm{Li}_{8} \mathrm{CoO}_{6}$, $\mathrm{Li}_{2} \mathrm{O}_{2}, \mathrm{Li}_{2} \mathrm{O}$ and $\mathrm{MgO}$ was $6 \times 6 \times 6,8 \times 8 \times 8,4 \times 4 \times 4$, $4 \times 4 \times 4,4 \times 4 \times 2,6 \times 6 \times 6,7 \times 7 \times 7$, and $8 \times 8 \times 8$, respectively. Gaussian broadening with an energy width of 0.1 $\mathrm{eV}$ was used for the Brillouin zone integration. These choices are sufficient to converge the bulk energies to better than $2 \mathrm{meV}$ per primitive cell, which is substantially smaller than the variation due to the use of different functionals.

$\mathrm{LiCoO}_{2}$ supercells with a defect $X$ were calculated employing $4 \times 4 \times 2$ supercells built from the primitive rhombohedral unit cell and $2 \times 2 \times 3$ Monkhorst-Pack k-point meshes. The defects and defect complexes that were studied are shown schematically in Fig. 1. The extrinsic $\mathrm{Mg}$ defects were created by the substitution of a Co or $\mathrm{Li}$ atom in the $\mathrm{Li}_{32} \mathrm{Co}_{32} \mathrm{O}_{64}$ supercell. The $\mathrm{Li}$ vacancy site was built by removing a Li from the supercell while the $\mathrm{Li}$ interstitial-site was constructed by adding a $\mathrm{Li}$ atom at the tetrahedral site in the Li layer. To simulate the $\mathrm{Mg}_{C o}-\mathrm{Li}_{i}$ and $\mathrm{Mg}_{L i}-\mathrm{V}_{L i}$ defect complexes in our supercell, we evaluated various configurations where the intrinsic Li defects were a first, second or third neighbors of the $\mathrm{Mg}$ site. These preliminary calculations indicated that the complexes are more stable when the Li defects are first neighbor to $\mathrm{Mg}$. We found similar results for the $\mathrm{Mg}_{C o}-\mathrm{Mg}_{L i}$ complex. Therefore, the extrinsic $\mathrm{Mg}$ defect is always a nearest neighbor of the second defect in the defect complexes that were studied. For each defect, all atomic positions were optimized until residual forces were less than $0.02 \mathrm{eV} / \AA$. The volume of the supercell with the defects was fixed to that calculated for the primitive unit cell.

The use of supercells to study defects introduces quantum mechanical, elastic and electrostatic artifacts $\frac{57}{}$ These artifacts become smaller as the supercell size is increased. In the present calculations, where we evaluated formation energies for neutral defects, only quantum mechanical (wavefunction overlap) and elastic effects are expected. We performed calculations with a larger $4 \times 4 \times 4$ supercell to corroborate that the formation energies evaluated with a $4 \times 4 \times 2$ supercell are relatively insensitive to these supercell size effects. For the substitution of $\mathrm{Mg}$ onto a Co site in $\mathrm{LiCoO}_{2}$, the formation energy evaluated with the $4 \times 4 \times 2$ supercell is $0.52 \mathrm{eV}$ while with the $4 \times 4 \times 4$ cell it is $0.55 \mathrm{eV}$. For the $\mathrm{Mg}_{C o}-\mathrm{Mg}_{L i}$ complex, the formation energies calculated with the $4 \times 4 \times 2$ and $4 \times 4 \times 4$ supercells are $0.71 \mathrm{eV}$ and $0.67 \mathrm{eV}$, respectively. We also evaluated the effect of volume relaxation for the substitution of $\mathrm{Mg}$ onto Co with the $4 \times 4 \times 2$ supercell; the formation energy is $0.51 \mathrm{eV}$ when volume relaxation is allowed, a $0.01 \mathrm{eV}$ difference from the fixed volume result.

The formation energies and electronic properties of metal-oxides are known to deviate from experimental results when evaluated with the generalized gradient approximation (GGA) to DFT, $\underline{52}$ Wang et al. have identified the overbinding of the $\mathrm{O}_{2}$ molecule and the selfinteraction of localized $d$-electrons in the transition metal as the main source of errors $\stackrel{52}{\underline{n}}$ Various methods have been proposed to account for these errors $\underline{49,52,53,67}$ One straightforward approach to correct the $\mathrm{O}_{2}$ overbinding is to add an empirical correction ${ }^{52,67}$ ? We have adopted this approach for all GGA-based calculations by adding a recently proposed $\underline{67}$ correction of $+1.20 \mathrm{eV}$ to the total energy of $\mathrm{O}_{2}$. Our calculated dissociation energy of $\mathrm{O}_{2}$ 

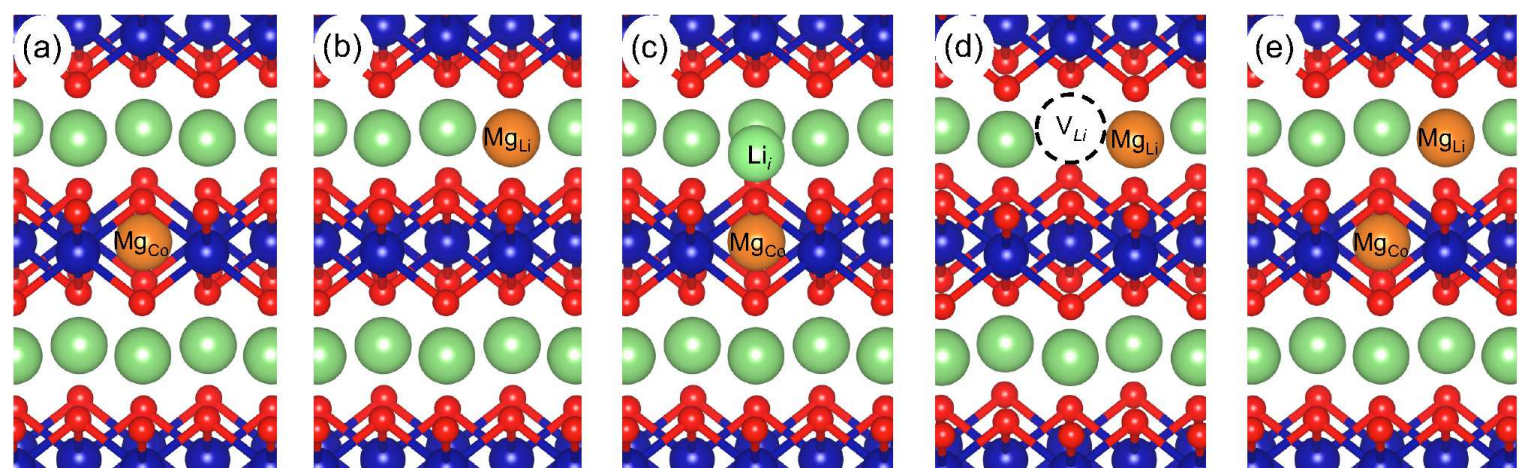

FIG. 1. Structures of Mg-doped $\mathrm{LiCoO}_{2}$ : a) $\mathrm{Mg}_{C o}$, $\mathrm{Mg}$ on a Co site; b) $\mathrm{Mg}_{L i}$, Mg on a Li site; c) $\mathrm{Mg}_{C o}-\mathrm{Li}_{i}$, complex of $\mathrm{Mg}_{C o}$ and a $\mathrm{Li}$ interstitial; d) $\mathrm{Mg}_{L i}-\mathrm{V}_{L i}$, complex of $\mathrm{Mg}_{L i}$ and a $\mathrm{Li}$ vacancy; and e) $\mathrm{Mg}_{C o}-\mathrm{Mg}_{L i}$, complex of $\mathrm{Mg}_{C o}$ and $\mathrm{Mg}_{L i}$. Colored spheres indicate $\mathrm{Mg}$ (orange), Li (green), Co (blue), and O (red) atoms, respectively. Image generated with VESTA.66

is $-4.85 \mathrm{eV}$ after correction while the GGA uncorrected value is $-6.05 \mathrm{eV}$; the corresponding experimental value is $-5.13 \mathrm{eV} \stackrel{69}{ }$ The self-interaction error can be treated with an onsite Hubbard model correction $\stackrel{47}{ }$ We used the rotational invariant approach of Dudarev $\stackrel{70}{\underline{70}}$ where a Coulomb parameter $\mathrm{U}$ and exchange parameter $\mathrm{J}$ are combined into a single U-J parameter. For simplicity, we hereafter refer to U instead of U-J. The electronic states and energetics calculated with this method can depend on the chosen value of $U . \underline{48,52}$ To study how the properties of Mg-doped $\mathrm{LiCoO}_{2}$ changes with $\mathrm{U}$, we performed calculations with $\mathrm{U}=1.5,3.3,5.0$, and $5.5 \mathrm{eV}$. We used the $\mathrm{U}$ parameter consistently for Co in all calculations, including metallic Co. Note that within this DFT $+\mathrm{U}$ and empirical correction scheme the energies of $\mathrm{s}$ and $\mathrm{p}$ orbitals are not directly affected, leaving the well known GGA binding energy errors $67,71,72$ untreated except for the case of the $\mathrm{O}_{2}$ molecule.

\section{Chemical Potentials}

To evaluate Eq. (11), we need to determine the atomic chemical potentials $\mu_{i}$. The quaternary Li-Co-Mg-O phase diagram is available in the Materials Project $54,73,74$ website $\stackrel{75}{ }$ From this phase diagram, one can expect separated $\mathrm{Li}-\mathrm{Co}-\mathrm{O}$ and $\mathrm{MgO}$ phases. Note that these are the known Li-Co-Mg-O phases but additional phases could exist. Based on this phase diagram, we approximate the atomic chemical potentials $\mu_{i}$ assuming that $\mathrm{LiCoO}_{2}$ is stable and in contact with $\mathrm{MgO}$.

The stability condition of $\mathrm{LiCoO}_{2}$ requires that:

$$
\Delta \mu_{L i}+\Delta \mu_{C o}+2 \Delta \mu_{O}=\Delta H^{f}\left(\mathrm{LiCoO}_{2}\right)
$$

where $\Delta H^{f}$ is the formation enthalpy and $\Delta \mu_{L i}=$ $\mu_{L i}^{L i C o O_{2}}-\mu_{L i}^{L i i_{b u l k}}, \Delta \mu_{C o}=\mu_{C o}^{L i C o O_{2}}-\mu_{C o}^{C o b u l k}$ and $\Delta \mu_{O}=\mu_{O}^{\mathrm{LiCOO}_{2}}-\mu_{O}^{\mathrm{O}_{2} \text { (gas) }} . \Delta \mu_{i}$ indicates $50,76.77$ the possible variation of the chemical potential of atom $i$ when $\mathrm{LiCoO}_{2}$ is formed, where $\mu_{i}^{\mathrm{LiCoO}_{2}}$ characterizes the chemical potential of atom $i$ in $\mathrm{LiCoO}_{2}$, and $\mu_{i}^{i_{\text {butk }}}$ and $\mu_{O}^{O_{2}(\text { gas })}$ the potential of atom $i$ in bulk and an $\mathrm{O}$ atom in $\mathrm{O}_{2}$. Absence of segregation of bulk $\mathrm{Li}$, Co or formation of $\mathrm{O}_{2}$ gas implies that $\Delta \mu_{i} \leq 0$. Additionally, $\mathrm{LiCoO}_{2}$ competes with other possible $\mathrm{Li}-\mathrm{Co}-\mathrm{O}$ compounds, such as $\mathrm{Li}_{2} \mathrm{O}, \mathrm{Li}_{2} \mathrm{O}_{2}, \mathrm{Li}_{8} \mathrm{CoO}_{6}, \mathrm{Li}_{6} \mathrm{CoO}_{4}, \mathrm{CoO}$ and $\mathrm{Co}_{3} \mathrm{O}_{4} \underline{\underline{49}}-\underline{\underline{51}}$ Therefore, the chemical potentials are also constrained by:

$$
x \Delta \mu_{L i}+y \Delta \mu_{C o}+z \Delta \mu_{O} \leq \Delta H^{f}\left(L i_{x} C o_{y} O_{z}\right)
$$

For $\mathrm{MgO}$, the stability condition requires:

$$
\Delta \mu_{M g}+\Delta \mu_{O}=\Delta H^{f}(M g O)
$$

where $\Delta \mu_{M g}=\mu_{M g}^{M g O}-\mu_{M g}^{M g_{b u l k}}$.

After accounting for all constraints, the range of $\mathrm{Li}$ and $\mathrm{O}$ chemical potentials that stabilize $\mathrm{LiCoO}_{2}$ are defined in the $\left(\Delta \mu_{L i}, \Delta \mu_{O}\right)$ plane. For a given point in this plane, $\mu_{\mathrm{Co}}^{\mathrm{LiCO}_{2}}$ is determined from Eq. (3) and $\mu_{\mathrm{Mg}}^{\mathrm{MgO}}$ from Eq. (5).

\section{RESULTS AND DISCUSSION}

\section{A. Range of Chemical Potentials}

To determine the chemical potential range of $\mathrm{Li}$ and $\mathrm{O}$ that stabilize $\mathrm{LiCoO}_{2}$, we evaluated $\Delta H^{f}$ of stable Li-CoO compounds $\underline{49}-\underline{51}$ The results from GGA and GGA $+\mathrm{U}$ are given in Table【. The formation enthalpy of $\mathrm{MgO}$ and available experimental and previously calculated $\Delta H^{f}$ values are also included in Table I] Our calculated formation enthalpies are in general agreement with previous GGA and GGA $+\mathrm{U}$ calculations,$\underline{50-52}$ particularly for the non-transition metal-oxides and for GGA calculations. For the GGA+U results of Co-oxides some differences can be noticed. For instance, our calculated formation energy for $\mathrm{LiCoO}_{2}$ with $\mathrm{U}=3.3$ and $5.0 \mathrm{eV}$ is $0.7-0.8$ 
TABLE I. Experimental ${ }^{78,79}$ (at $\mathrm{T}=298 \mathrm{~K}$ ) and calculated formation enthalpy of Li-Co-O compounds and MgO in eV. Results from GGA $(\mathrm{U}=0)$ and $\mathrm{GGA}+\mathrm{U}$ calculations with $\mathrm{U}=1.5,2.4,3.3,5.0$ and $5.5 \mathrm{eV}$ are included. Previous GGA and GGA+U results are included for comparison. The enthalpies of $\mathrm{MgO}, \mathrm{Li}_{2} \mathrm{O}$, and $\mathrm{Li}_{2} \mathrm{O}_{2}$ are $\mathrm{U}$ independent.

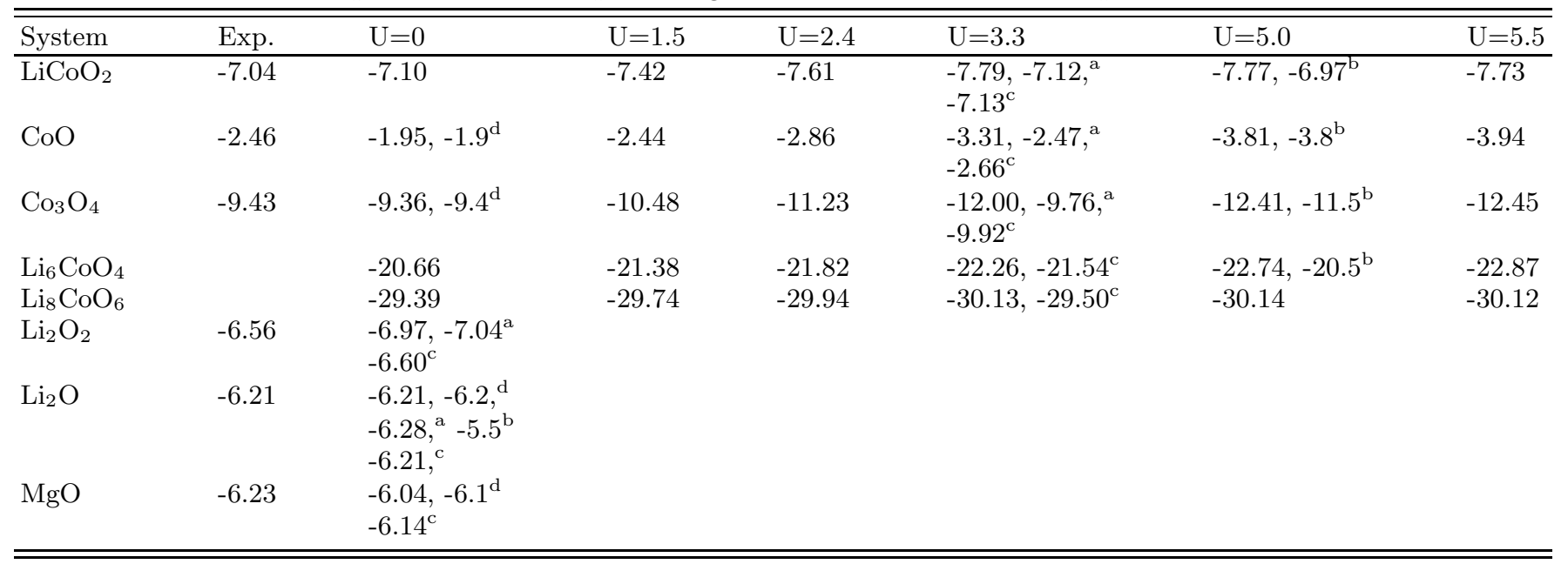

a Ref. 50

b Ref. 51

c Ref. 54, 74, and 75

d Ref. 52

$\mathrm{eV}$ lower than the values in Refs. 50? ,51. The formation energy of $\mathrm{CoO}$ and $\mathrm{Co}_{3} \mathrm{O}_{4}$ evaluated with $\mathrm{GGA}+\mathrm{U}$ also differs from Refs. 50? but resemble the results in Ref. 51. The source of the discrepancy between our results and Ref. 50 is unclear. The discrepancy with the results of Ref. 51 arises mainly because a correction factor for the $\mathrm{O}_{2}$ overbinding was not used in that work.

We discuss first the deviation of our calculated formation enthalpies from the available experimental results to have an overall idea on the accuracy of the calculated chemical potentials. Note that the calculated formation enthalpies are at $\mathrm{T}=0 \mathrm{~K}$ while the experimental results are at $\mathrm{T}=298 \mathrm{~K}$. However, the difference between $0 \mathrm{~K}$ and $298 \mathrm{~K}$ enthalpies is relatively small, within $0.1 \mathrm{eV}$ per mol of $\mathrm{O}_{2}$ for most transition metal-oxides $\frac{52}{2}$ Fig. 2 shows the deviation between calculated and experimental formation enthalpy. GGA reproduces the formation enthalpy of non-transition metal-oxides $\left(\mathrm{Li}_{2} \mathrm{O}, \mathrm{Li}_{2} \mathrm{O}_{2}\right.$, and $\mathrm{MgO}$ ) after correcting for the $\mathrm{O}_{2}$ overbinding $\underline{52.67}$ The error on the formation enthalpy of $\mathrm{Li}_{2} \mathrm{O}$ and $\mathrm{MgO}$ is within $0.2 \mathrm{eV}$. For $\mathrm{Li}_{2} \mathrm{O}_{2}$, the error is $0.41 \mathrm{eV}$.

The formation enthalpy of Co-oxides evaluated within GGA are expected to deviate from experiment due to the self-interaction of localized $d$-electrons $\stackrel{48.52}{=}$ The deviation on the formation enthalpy of $\mathrm{CoO}$ evaluated with GGA is close to $0.50 \mathrm{eV}$. For $\mathrm{LiCoO}_{2}$ and $\mathrm{Co}_{3} \mathrm{O}_{4}$, the corresponding deviation is relatively small, less than 0.1 $\mathrm{eV}$. However, the oxidation energy of $\mathrm{CoO}\left(6 \mathrm{CoO}+\mathrm{O}_{2}\right.$ $\rightarrow 2 \mathrm{Co}_{3} \mathrm{O}_{4}$ ) is $-7.04 \mathrm{eV}$, when evaluated with GGA, while the experimental value is $-4.08 \mathrm{eV}$. GGA+U with $\mathrm{U}=$ $1.5 \mathrm{eV}$ leads to a lower deviation of the formation enthalpy of $\mathrm{CoO}(0.03 \mathrm{eV})$ from experiment, but a greater deviation for $\mathrm{LiCoO}_{2}(0.38 \mathrm{eV})$ and $\mathrm{Co}_{3} \mathrm{O}_{4}(1.19 \mathrm{eV})$.

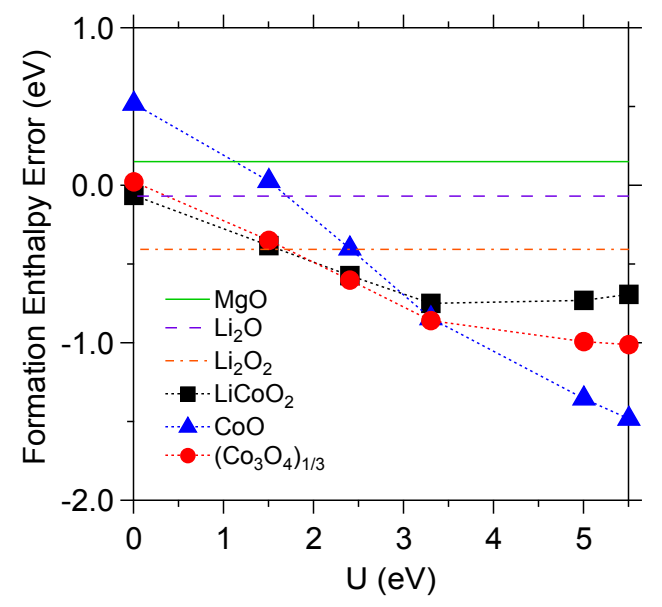

FIG. 2. Deviation between experimental and calculated formation enthalpies as function of U. Note that for the Cooxides the error is per Co atom.

The oxidation energy of $\mathrm{CoO}$ is also large, $-6.34 \mathrm{eV}$, a $2.26 \mathrm{eV}$ error. The agreement with experiment for the oxidation of $\mathrm{CoO}$ is better when it is calculated with $\mathrm{U}$ $=3.3 \mathrm{eV} ; \underline{52}$ the calculated oxidation energy is $-4.15 \mathrm{eV}$, only an $0.07 \mathrm{eV}$ error. However, the error in the formation enthalpy of $\mathrm{LiCoO}_{2}, \mathrm{CoO}$ and $\mathrm{Co}_{3} \mathrm{O}_{4}$ is above 0.70 $\mathrm{eV}$ when evaluated with $\mathrm{U}=3.3 \mathrm{eV}$. As shown in Fig. 2 , the agreement for the oxidation energy of $\mathrm{CoO}$ may be due to error cancelation because the error per Co atom of the formation energy of $\mathrm{CoO}$ and $\mathrm{Co}_{3} \mathrm{O}_{4}$ is the same for $\mathrm{U}=3.3 \mathrm{eV}$. For $\mathrm{U}$ values over $3.3 \mathrm{eV}$, the formation enthalpies and relative energies of $\mathrm{CoO}$ and $\mathrm{Co}_{3} \mathrm{O}_{4}$ deviate 
from experimental results by more than $1 \mathrm{eV}$.

The enthalpy of formation of $\mathrm{LiCoO}_{2}$ is less sensitive to the $\mathrm{U}$ value than $\mathrm{CoO}$ and $\mathrm{Co}_{3} \mathrm{O}_{4}$. For $\mathrm{U}$ values from 3.3 to $5.5 \mathrm{eV}$, the deviation on the formation enthalpy of $\mathrm{LiCoO}_{2}$ is centered on $0.7 \mathrm{eV}$. $\mathrm{U}$ values in this range are commonly used to study different processes and properties of $\mathrm{LiCoO}_{2}$. U $=2.9 \mathrm{eV}$ was used to study the electronic structure of $\mathrm{LiCoO}_{2}, \underline{80} \mathrm{~A} \mathrm{U}$ value of $3.3 \mathrm{eV}$ has been used to study the phase diagram and surface properties of $\mathrm{LiCoO}_{2} \stackrel{50}{\underline{50}}$ This is also the value adopted for Co in the Materials Project. This value of U was established from a fit to the experimental oxidation energy of $\mathrm{CoO}$ and the methodology of Wang et al $\underline{52}^{2}$ to correct for the $\mathrm{O}_{2}$ overbinding. $\mathrm{U}$ values close to $5.0 \mathrm{eV}$ were used to calculate the average Li-intercalation potential, $\stackrel{48,71}{=}$ and the defect chemistry ${ }^{51}$ in $\mathrm{LiCoO}_{2}$. U $=5.5 \mathrm{eV}$ has been used to study the phase diagram and thermal decomposition of $\mathrm{LiCoO}_{2} \stackrel{49}{\underline{49}} \mathrm{U}$ values close to $5.0 \mathrm{eV}$ or $5.5 \mathrm{eV}$ are taken from the self-consistently determined $\frac{48}{} \mathrm{U}$ value of Co in layered $\mathrm{LiCoO}_{2}$ or the average of $\mathrm{U}$ values of $\mathrm{Co}$ in different Co-oxides.

Clearly, the GGA+U method is limited in accuracy for relative energies of metal-oxides, even when empirically choosing $\mathrm{U}$. This is not unexpected as the $\mathrm{U}$ parameter should be sensitive to the chemical environment of the atom sites where the correction is applied $\underline{\underline{48}}$ To calculate formation enthalpy of metal-oxides, the main problem is using the same $U$ value to describe the atom sites in the metallic state (reactant) and the oxides (product). The method proposed by Jain et al..$^{53}$ and used in the Material Project is a possible solution to this problem. Formation enthalpies evaluated with this method are in reasonable agreement with experiments $\underline{\underline{53}}$ Yet, Jain's method relies on $U$ values determined to describe formation enthalpies or oxidation energy of metal-oxides. This limits the usefulness of the method to study defects, as the $\mathrm{U}$ values are not necessarily transferable. As exemplified by $\mathrm{LiCoO}_{2}$, a single $U$ value cannot describe all properties, not even formation enthalpies and oxidation energies of the known parent phases of transition metal oxides to reasonable accuracy $(<0.5 \mathrm{eV})$.

We now discuss the phase stability diagram of $\mathrm{LiCoO}_{2}$ and competing phases evaluated with GGA and GGA+U (Fig. 3). We have limited our analysis to the listed LiCo-O compounds as these are the known or expected ${ }^{49}$ thermally stable phases. For each diagram in Fig. 3, the colored polygon shows the range of $\mathrm{O}$ and $\mathrm{Li}$ chemical potentials that stabilize $\mathrm{LiCoO}_{2}$. The reference for the chemical potential of $\mathrm{O}$ and $\mathrm{Li}$ is the $\mathrm{O}_{2}$ molecule at 0 $\mathrm{K}$ and metallic lithium, respectively. The chemical potential of gaseous oxygen is dependent on temperature and partial pressure. One can approximate the chemical potential of gaseous oxygen assuming it to be an ideal gas on the basis of experimental data $\underline{69}$ For instance, at ambient pressure and $1200 \mathrm{~K}, 900 \mathrm{~K}$ and $298 \mathrm{~K}$, it is approximately $1.5,1.0$ and $0.3 \mathrm{eV}$ below $\mu_{O}^{O_{2}(g a s)}$.

Fig. 3(a) shows the chemical potential diagram constructed from available experimental formation enthalpy
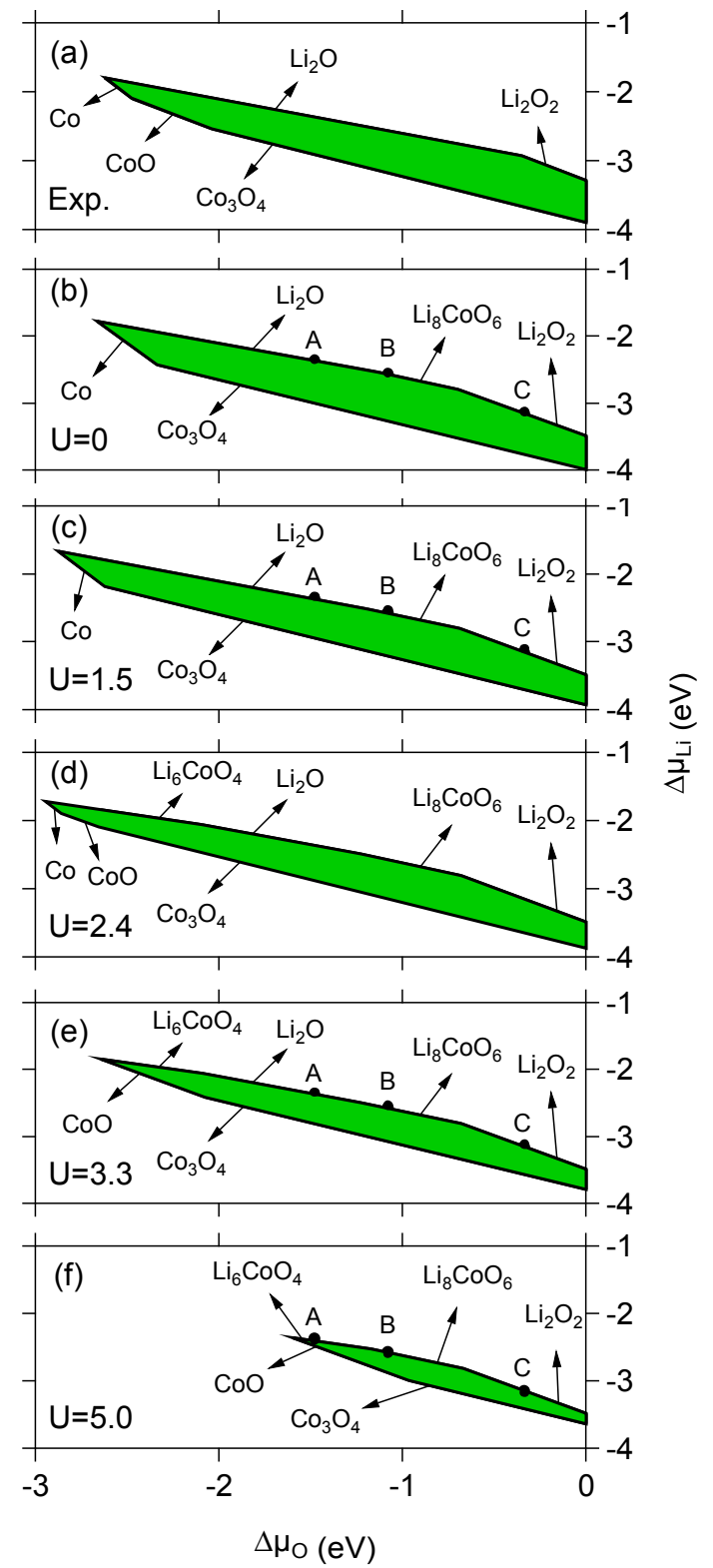

FIG. 3. Boundaries of the stable region of $\mathrm{LiCoO}_{2}$ in the $\mathrm{O}$ and $\mathrm{Li}$ chemical potentials. The boundaries were constructed with the formation enthalpy from (a) experiment, (b) GGA and GGA+U with $\mathrm{U}$ values of (c) 1.5, (d) 2.4, (e) 3.3 and (f) $5.0 \mathrm{eV}$. The filled circles A, B, and C indicates the chemical potentials where defect formation energies were evaluated.

of Li-Co-O compounds at T $=298$ K $\stackrel{78,79}{7}$ Fig. 3(b), (c), (d), (e) and (f) correspond to the phase diagrams from GGA and GGA $+\mathrm{U}$ calculations with $\mathrm{U}=1.5,2.4,3.3$ and $5.0 \mathrm{eV}$, respectively. All calculations predict a range of $\mathrm{O}$ and $\mathrm{Li}$ chemical potentials where $\mathrm{LiCoO}_{2}$ is stable. Yet, the potential ranges differ from experiment and are noticeably sensitive to the $\mathrm{U}$ value. For instance, the maximum oxygen chemical potential where $\mathrm{LiCoO}_{2}$ is stable change from $-2.88 \mathrm{eV}$ for calculations with $\mathrm{U}=$ $1.5 \mathrm{eV}$ to only $-1.60 \mathrm{eV}$ for $\mathrm{U}=5.0 \mathrm{eV}$. Moreover, only 
calculations with $\mathrm{U} \sim 2.4 \mathrm{eV}$ reproduces all the phases that are in equilibrium with $\mathrm{LiCoO}_{2}$. GGA and GGA+U with $\mathrm{U}=1.5 \mathrm{eV}$ predict the equilibrium between metallic $\mathrm{Co}$ and $\mathrm{LiCoO}_{2}$ phases but not the equilibrium with the $\mathrm{CoO}$ phase (i.e. it is missing from the phase diagram). On the other hand, GGA+U with a $\mathrm{U}$ value of $3.3 \mathrm{eV}$ or higher show the equilibrium of $\mathrm{LiCoO}_{2}$ with $\mathrm{CoO}$ but not with metallic Co.

Based on these phase diagrams, we studied the extrinsic $\mathrm{Mg}$ defects in $\mathrm{LiCoO}_{2}$ under three different chemical conditions, labeled as A, B and C. The chemical conditions A, B, and C corresponds to Li-rich condition at 0.2 atm oxygen and $1200 \mathrm{~K}, 900 \mathrm{~K}$ and $298 \mathrm{~K}$, respectively. These conditions are indicated as filled circles in Fig. 3 .

\section{B. Defect Formation Energies}

The electronic species formed upon the substitution of $\mathrm{Mg}$ on $\mathrm{Co}$ and $\mathrm{Li}$ sites can be in one of multiple spin configurations. To identify the configuration with the lowest energy, we examined various spin configurations for each defect. Similarly, spin configurations were evaluated for the $\mathrm{Li}_{i}$ and $\mathrm{V}_{L i}$ defects. The defect complexes of $\mathrm{Mg}$ have non-polarized spin configurations. The formation energy of $\mathrm{Mg}_{C o}, \mathrm{Mg}_{L i}, \mathrm{Mg}_{C o}-\mathrm{Li}_{i}, \mathrm{Mg}_{L i}-\mathrm{V}_{L i}$ and $\mathrm{Mg}_{C o}-\mathrm{Mg}_{L i}$ are shown in Fig. 4 as a function of $\mathrm{U}$ for a representative chemical condition. We also included the formation energy of $\mathrm{Li}_{i}$ and $\mathrm{V}_{L i}$. The chemical condition correspond to point A in Fig. 3, representing the most Li-rich condition during synthesis at $1200 \mathrm{~K}$.

As previously discussed, the formation of $\mathrm{Mg}_{C o}$ and $\mathrm{Mg}_{L i}$ leads to changes on the valency of Co atoms in $\mathrm{LiCoO}_{2}$. As a result, the formation energy of these defects depends on the U value, Fig. 廿(a). The change in the slope of the formation energy of $\mathrm{Mg}_{C o}$ and $\mathrm{Mg}_{L i}$ at $\mathrm{U}=3.3$ and $1.5 \mathrm{eV}$, respectively, corresponds to a transition from delocalized (low U) to localized (high U) states; see discussion in the next section. The same $U$ dependence is also found in the formation energy of the $\mathrm{V}_{L i}$ and $\mathrm{Li}_{i}$ point defects since the valency of Co atoms also changes upon formation of these defects. The result for the formation energy of $\mathrm{V}_{L i}$ as function of $\mathrm{U}$ resembles previous calculations of the Li-insertion volt-

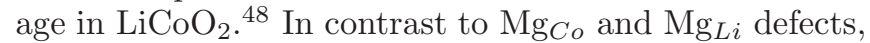
formation of the $\mathrm{Mg}$ defect complexes do not change the valency of $\mathrm{Co}$ in $\mathrm{LiCoO}_{2}$ and their formation energies are rather insensitive to U, Fig. 4(b).

These results show the difficulty of studying $\mathrm{Mg}$ doping in $\mathrm{LiCoO}_{2}$ employing GGA and GGA+U calculations. For instance, the preferred site location of $\mathrm{Mg}$ changes with the $\mathrm{U}$ value. $\mathrm{Mg}$ is preferentially located on Co sites for calculations with GGA and GGA $+U$ with $U$ below $5.0 \mathrm{eV}$, which is in line with experiments $11,12,15,22,25-31,81$ showing that $\mathrm{Mg}$ is located at Co site. For calculations with $\mathrm{U}=5.0$ and $5.5 \mathrm{eV}$, however, $\mathrm{Mg}$ is equally stable on both $\mathrm{Co}$ and $\mathrm{Li}$ sites. Moreover, only GGA $+\mathrm{U}$ with $\mathrm{U}$ values around $1.5 \mathrm{eV}$ predict the spontaneous formation

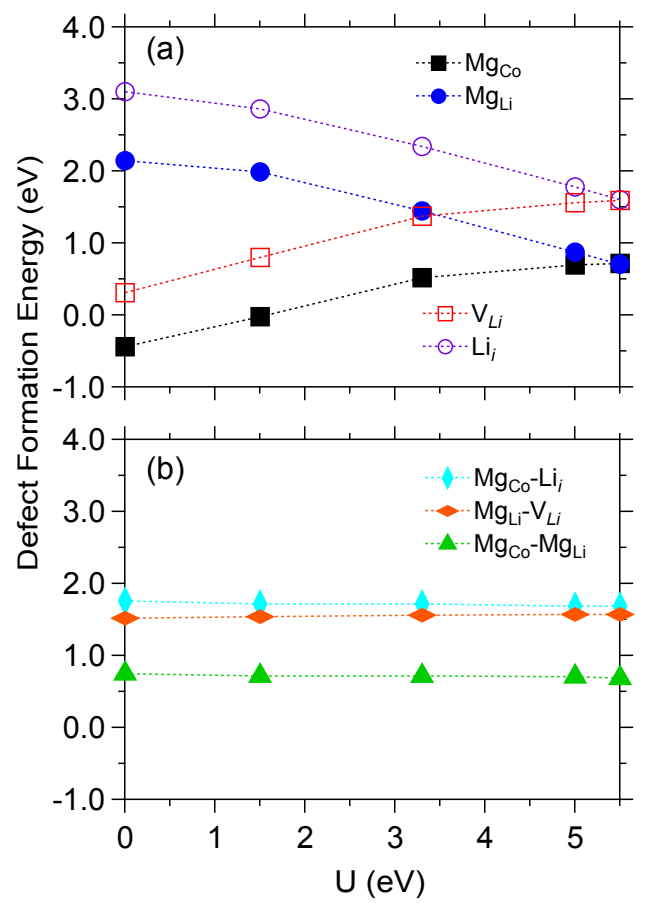

FIG. 4. Formation energy of (a) Mg and Li defects and (b) their complexes in $\mathrm{LiCoO}_{2}$ as function of $\mathrm{U}$. The energies are obtained at point $\mathrm{A}$ in the chemical potential diagram. Note overlapping symbols in (a) at the value $\mathrm{U}=5.5$.

of Mg-doped $\mathrm{LiCoO}_{2}$. The formation energy of $\mathrm{Mg}_{\mathrm{Co}}$ is $-0.44 \mathrm{eV}$ and $-0.02 \mathrm{eV}$ for GGA and $\mathrm{GG}+\mathrm{U}$ with $\mathrm{U}=$ $1.5 \mathrm{eV}$, respectively. GGA+U calculations with $\mathrm{U}$ values of $3.3,5.0$ and $5.5 \mathrm{eV}$ yield $\mathrm{Mg}_{\mathrm{Co}}$ formation energies of $0.52,0.70$ and $0.72 \mathrm{eV}$, respectively, predicting that $\mathrm{Mg}$ will have a low solubility in $\mathrm{LiCoO}_{2}$. However, Mgdoped $\mathrm{LiCoO}_{2}$ with $\mathrm{Mg} / \mathrm{Co}$ ratio as high as 0.5 have been synthesized, 26 demonstrating that this is not the case.

The formation energy of the $\mathrm{Mg}$ defects in $\mathrm{LiCoO}_{2}$ depend on the atomic chemical potentials. We list in Table Ihe formation energy of $\mathrm{Mg}$ defects in $\mathrm{LiCoO}_{2}$ for various chemical potentials. These potentials represent Li-rich environment and $0.2 \mathrm{~atm} \mathrm{O}_{2}$ at (A) 1200, (B) 900 and $(\mathrm{C}) 298 \mathrm{~K}$. The formation energy of $\mathrm{Mg}_{\mathrm{Co}}$ is reduced from point $\mathrm{A}$ to $\mathrm{B}$ and $\mathrm{C}$ while that of $\mathrm{Mg}_{L i}$ increases. Only GGA $+\mathrm{U}$ with $\mathrm{U}=1.5 \mathrm{eV}$ predicts $\mathrm{Mg}$ to be easily soluble in $\mathrm{LiCoO}_{2}$ at points $\mathrm{A}, \mathrm{B}$ and $\mathrm{C}$. For greater $\mathrm{U}$ values, $\mathrm{Mg}_{C o}$ is energetically unfavorable at all points.

Table II also includes the formation and binding energy of the $\mathrm{Mg}_{C o}-\mathrm{Li}_{i}, \mathrm{Mg}_{L i}-\mathrm{V}_{L i}$ and $\mathrm{Mg}_{C o}-\mathrm{Mg}_{L i}$ complexes. The $\mathrm{Mg}_{C o}-\mathrm{Li}_{i}$ and $\mathrm{Mg}_{L i}-\mathrm{V}_{L i}$ complexes have high formation energies, from 1.1 to $2.2 \mathrm{eV}$ at the various atomic chemical potentials and binding energy from 1.3 to $0.6 \mathrm{eV}$. The $\mathrm{Mg}_{C o}-\mathrm{Mg}_{L i}$ complex has a formation energy close to $0.7 \mathrm{eV}$ that is independent of the chemical potential and with binding energies from 0.7 to $1.3 \mathrm{eV}$. Although the formation energy of $\mathrm{Mg}_{C o}-\mathrm{Mg}_{L i}$ is high, it is the lowest for $\mathrm{U}=5.5 \mathrm{eV}$ at point $\mathrm{A}$ and often within 
TABLE II. Calculated formation energy of $\mathrm{Mg}$ and $\mathrm{Li}$ defects and binding energy (BE) of their complexes in $\mathrm{LiCoO}_{2}$ and in $\mathrm{eV}$. Results from GGA $(\mathrm{U}=0)$ and $\mathrm{GGA}+\mathrm{U}$ calculations with $\mathrm{U}=1.5,3.3,5.0$ and $5.5 \mathrm{eV}$ are included. The points $\mathrm{A}, \mathrm{B}$ and $\mathrm{C}$ indicates the chemical potentials that were examined, corresponding to Li-rich condition and 0.2 atm $\mathrm{O}_{2}$ at A: $1200 \mathrm{~K}$, B: $900 \mathrm{~K}$ and C: $298 \mathrm{~K}$.

\begin{tabular}{|c|c|c|c|c|c|c|c|c|c|c|c|c|c|c|c|c|c|c|c|c|}
\hline \multirow[b]{2}{*}{ Defects } & \multicolumn{4}{|c|}{$\mathrm{U}=0$} & \multicolumn{4}{|c|}{$\mathrm{U}=1.5$} & \multicolumn{4}{|c|}{$\mathrm{U}=3.3$} & \multicolumn{4}{|c|}{$\mathrm{U}=5$} & \multicolumn{4}{|c|}{$\mathrm{U}=5.5$} \\
\hline & $\mathrm{A}$ & $\mathrm{B}$ & $\mathrm{C}$ & $\mathrm{BE}$ & $\mathrm{A}$ & $\mathrm{B}$ & $\mathrm{C}$ & $\mathrm{BE}$ & $\mathrm{A}$ & $\mathrm{B}$ & $\mathrm{C}$ & $\mathrm{BE}$ & $\mathrm{A}$ & B & $\mathrm{C}$ & $\mathrm{BE}$ & $\mathrm{A}$ & B & $\mathrm{C}$ & $\mathrm{BE}$ \\
\hline $\mathrm{Mg}_{C o}$ & -0.44 & -0.64 & -0.80 & & -0.02 & -0.22 & -0.38 & & 0.52 & 0.32 & 0.16 & & 0.70 & 0.50 & 0.34 & & 0.72 & 0.52 & 0.36 & \\
\hline $\mathrm{Mg}_{L i}$ & 2.15 & 2.34 & 2.50 & & 1.99 & 2.19 & 2.35 & & 1.45 & 1.66 & 1.82 & & 0.88 & 1.08 & 1.24 & & 0.71 & 0.91 & 1.07 & \\
\hline $\mathrm{Li}_{i}$ & 3.10 & 3.30 & 3.88 & & 2.86 & 3.06 & 3.64 & & 2.34 & 2.54 & 3.12 & & 1.78 & 1.98 & 2.57 & & 1.60 & 1.80 & 2.38 & \\
\hline $\mathrm{V}_{L i}^{i}$ & 0.31 & 0.11 & -0.48 & & 0.80 & 0.60 & 0.02 & & 1.38 & 1.18 & 0.60 & & 1.56 & 1.36 & 0.78 & & 1.59 & 1.39 & 0.81 & \\
\hline $\mathrm{Mg}_{C o}-\mathrm{Li}_{i}$ & 1.76 & 1.76 & 2.18 & 0.90 & 1.72 & 1.72 & 2.14 & 1.12 & 1.72 & 1.72 & 2.14 & 1.14 & 1.69 & 1.69 & 2.11 & 0.79 & 1.69 & 1.69 & 2.11 & 0.63 \\
\hline $\mathrm{Mg}_{L i}-\mathrm{V}_{L i}$ & 1.52 & 1.52 & 1.10 & 0.92 & 1.54 & 1.54 & 1.12 & 1.24 & 1.56 & 1.56 & 1.14 & 1.28 & 1.57 & 1.57 & 1.14 & 0.88 & 1.57 & 1.57 & 1.14 & 0.73 \\
\hline $\mathrm{Mg}_{C o}-\mathrm{Mg}_{L i}$ & 0.75 & 0.75 & 0.75 & 0.95 & 0.72 & 0.72 & 0.72 & 1.24 & 0.72 & 0.72 & 0.72 & 1.25 & 0.71 & 0.71 & 0.71 & 0.87 & 0.69 & 0.69 & 0.69 & 0.74 \\
\hline
\end{tabular}

a few $0.1 \mathrm{eV}$ elsewhere. The formation energy of these complexes is insensitive to the $\mathrm{U}$ value and we can state with some certainty that these complexes are unlikely to form in $\mathrm{Mg}$-doped $\mathrm{LiCoO}_{2}$ due to their high formation energies.

\section{Defect Geometries}

To study the local geometry around $\mathrm{Mg}$ in $\mathrm{LiCoO}_{2}$ as a function of $\mathrm{U}$, we have tabulated in Table III the $\mathrm{Mg}-\mathrm{O}$ and $\mathrm{Co}-\mathrm{O}$ interatomic distances calculated with GGA and GGA+U. For the $\mathrm{Mg}_{C o}$ and $\mathrm{Mg}_{L i}$ defects, we also include the magnetic moment of the supercell and whether it is localized or delocalized. The localization was determined based on the local magnetic moments.

For $\mathrm{Mg}_{\mathrm{Co}}$, both GGA and GGA+U predict a low-spin configuration. Yet, for calculations with $\mathrm{U}=3.3$ or below, the state is delocalized while for $\mathrm{U}=5.0 \mathrm{eV}$ or above, it is localized. When the state is delocalized, the $\mathrm{Mg}-\mathrm{O}$ distances are $2.04 \AA$ independently of the $\mathrm{U}$ value (Table III). The Co-O distances of Co atoms nearest to $\mathrm{Mg}_{\mathrm{Co}}$ are $1.94 \AA$, as in pristine $\mathrm{LiCoO}_{2}$, when calculated with GGA. For GGA+U with $\mathrm{U}=1.5$ and $3.3 \mathrm{eV}$, these Co$\mathrm{O}$ bonds are slightly distorted with distances of 1.94 and $1.93 \AA$. GGA+U results in a state that is delocalized mainly on the six Co atoms nearest to $\mathrm{Mg}_{C o}$ while GGA leads to a more delocalized state and undistorted Co-O bonds.

For the localized state predicted with $\mathrm{U}=5.0 \mathrm{eV}$, the $\mathrm{Mg}-\mathrm{O}$ bonds are distorted with distances ranging from 2.06 to $2.02 \AA$. A slightly higher $\mathrm{U}$ value, $5.5 \mathrm{eV}$, leads to higher distortion with $\mathrm{Mg}-\mathrm{O}$ distances ranging from 2.07 to $1.95 \AA$. This distortion on the $\mathrm{Mg}-\mathrm{O}$ bonds results from the formation of the localized holes on a Co atom near to $\mathrm{Mg}_{C o}$. The Co-O bonds where the hole is located are also distorted with distances from 1.92 to $1.90 \AA$ (Table III). Such bonds are shorter than $1.94 \AA$ for Co-O in pristine $\mathrm{LiCoO}_{2}$.

The impurity hole formed with $\mathrm{Mg}_{C o}$ in Mg-doped $\mathrm{LiCoO}_{2}$ can be compared with other hole that can be formed in $\mathrm{LiCoO}_{2}$. We performed calculations for the hole created with the formation of a $\mathrm{Li}$ vacancy; results are included in Table III. As for $\mathrm{Mg}_{C o}$, both GGA and $\mathrm{GGA}+\mathrm{U}$ predict a low-spin configuration, delocalized for calculations with $\mathrm{U}=3.3$ (or below) and localized for $\mathrm{U}$
$=5.0 \mathrm{eV}$ (or above). Another hole is the one formed as an intrinsic electronic defect in pristine $\mathrm{LiCoO}_{2}$. The formation of this state in $\mathrm{LiCoO}_{2}$ was recently studied 51 with $\mathrm{GGA}+\mathrm{U}(\mathrm{U}=5.0 \mathrm{eV})$ and methodologies similar to the present work. We therefore used this result for comparison. The intrinsic hole in $\mathrm{LiCoO}_{2}$ was found to be localized with a low-spin configuration and $\mathrm{Co}-\mathrm{O}$ distances of $1.91(\times 4)$ and $1.90(\times 2) \AA .51$ The properties of this hole are similar to the one formed with $\mathrm{Mg}_{C o}$; the main difference is the more distorted Co-O geometry in $\mathrm{Mg}$-doped $\mathrm{LiCoO}_{2}$.

For the impurity electron formed with the $\mathrm{Mg}_{L i}$ defect, GGA predicts a delocalized low-spin state. The Mg-O distances are all $2.08 \AA$ while the Co-O bonds are distorted with interatomic distances from 1.96 to $1.93 \AA$. The Li-O interatomic distance in pristine $\mathrm{LiCoO}_{2}$ is 2.11 $\AA$. All calculations of the $\mathrm{Mg}_{L i}$ defect with GGA+U result on a localized high-spin configuration. In this case, the $\mathrm{Mg}-\mathrm{O}$ bonds are distorted with distances ranging from 2.10 to $2.01 \AA$. The impurity electron is localized on a second nearest neighbor Co atom to $\mathrm{Mg}_{L i}$ with $\mathrm{Co}-\mathrm{O}$ distances that range from 2.10 to $2.03 \AA$. These distances do not change significantly for calculations with the various $U$ values.

The electron introduced with the $\mathrm{Mg}_{L i}$ defect is comparable to the electron introduced upon the formation of an interstitial $\mathrm{Li}$ atom in $\mathrm{LiCoO}_{2}$. GGA predicts a delocalized low-spin state and GGA $+\mathrm{U}$ a delocalized highspin state for $\mathrm{Li}_{i}$ as for the $\mathrm{Mg}_{L i}$ defect. The Co-O interatomic distances are also rather similar in both defects. For the electron as an intrinsic electronic defect in pristine $\mathrm{LiCoO}_{2}$, Koyama et al ${ }^{51}$ found a localized low-spin state with Co-O distances of $2.06(\times 6) \AA$.

In line with results for the formation energy, the characterization of the local geometry of defects that change the valency of Co atoms in $\mathrm{LiCoO}_{2}$ is rather difficult with GGA $+\mathrm{U}$ calculations. The geometry of these defects is sensitive to the $U$ value because increasing/decreasing $U$ leads to localized/delocalized defect states (see discussion below). The situation is different for defect complexes. The geometry of the $\mathrm{Mg}$ defect complexes in $\mathrm{LiCoO}_{2}$ does not depend on the $\mathrm{U}$ value. For all complexes the $\mathrm{Mg}-\mathrm{O}$ and $\mathrm{Co}-\mathrm{O}$ bonds are distorted with distances from 2.11 to $1.93 \AA$ for $\mathrm{Mg}-\mathrm{O}$ and from 1.95 to $1.92 \AA$ for $\mathrm{Co}-\mathrm{O}$ (Table III). For these type of defects that do not change the valency of $\mathrm{Co}, \mathrm{GGA}+\mathrm{U}$ calculations yield more con- 
TABLE III. Total magnetic moment ( $M M$ per supercell in bohr magneton $\left.\mu_{B}\right)$ and Mg-O and Co-O interatomic distances $(\AA)$ in $\mathrm{Mg}$-doped $\mathrm{LiCoO}_{2}$. Results are included for GGA and GGA+U calculations with $\mathrm{U}=1.5,3.3,5.0$ and $5.5 \mathrm{eV}$.

\begin{tabular}{|c|c|c|c|c|c|c|}
\hline Defects & Property & $\mathrm{U}=0$ & $\mathrm{U}=1.5$ & $\mathrm{U}=3.3$ & $\mathrm{U}=5$ & $\mathrm{U}=5.5$ \\
\hline \multirow{3}{*}{$\mathrm{Mg}_{C o}$} & $M M$ & $1-$ delocalized & $1-$ delocalized & $1-$ delocalized & $1-$ localized & $1-$ localized \\
\hline & $d(\mathrm{Mg}-\mathrm{O})$ & $2.04 \times 6$ & $2.04 \times 6$ & $2.04 \times 6$ & $\begin{array}{l}2.06 \times 2,2.03 \times 2, \\
2.02 \times 2\end{array}$ & $\begin{array}{l}2.07,2.04,2.03 \times 2, \\
2.01,1.95\end{array}$ \\
\hline & $d(\mathrm{Co}-\mathrm{O})$ & $1.94 \times 6$ & $1.94 \times 4,1.93 \times 2$ & $1.94 \times 4,1.93 \times 2$ & $\begin{array}{l}1.92 \times 2,1.91 \times 2 \\
1.90 \times 2\end{array}$ & $\begin{array}{l}1.92 \times 2,1.91 \times 2 \\
1.87 \times 2\end{array}$ \\
\hline \multirow{2}{*}{$\mathrm{V}_{L i}$} & $M M$ & 1 - delocalized & 1 - delocalized & 1 - delocalized & 1 - localized & $1-$ localized \\
\hline & $d(\mathrm{Co}-\mathrm{O})$ & $\begin{array}{l}1.95 \times 2,1.94 \times 2 \\
1.92 \times 2\end{array}$ & $\begin{array}{l}1.94 \times 2, \quad 1.93 \times 2, \\
1.92 \times 2\end{array}$ & $\begin{array}{l}1.94 \times 2,1.93 \times 2, \\
1.92 \times 2\end{array}$ & $\begin{array}{l}1.92 \times 2,1.91 \times 2, \\
1.89 \times 2\end{array}$ & $\begin{array}{l}1.92 \times 2,1.91 \times 2, \\
1.89 \times 2\end{array}$ \\
\hline \multirow[t]{4}{*}{$\operatorname{Mg}_{L i}$} & $M M$ & 1 - delocalized & $3-$ localized & 3 - localized & 3 - localized & 3 - localized \\
\hline & $d(\mathrm{Mg}-\mathrm{O})$ & $2.08 \times 6$ & $\begin{array}{l}2.09 \times 2,2.08 \times 2 \\
2.07,2.01\end{array}$ & $\begin{array}{l}2.10 \times 2,2.09 \\
2.08,2.06 \times 2\end{array}$ & $\begin{array}{l}2.10 \times 2,2.09 \\
2.08,2.06 \times 2\end{array}$ & $\begin{array}{l}2.10 \times 2,2.09 \\
2.08,2.06 \times 2\end{array}$ \\
\hline & $d(\mathrm{Co}-\mathrm{O})$ & $1.96 \times 2,1.94 \times 2$ & $2.08,2.06 \times 2$ & $2.10 \times 2,2.06$ & $2.10 \times 2,2.06$ & $2.10 \times 2,2.06$ \\
\hline & & $1.93 \times 2$ & $2.05 \times 3$ & $2.05,2.03 \times 2$ & $2.05,2.04 \times 2$ & $2.05,2.04 \times 2$ \\
\hline \multirow[t]{2}{*}{$\mathrm{Li}_{i}$} & $M M$ & 1 - delocalized & 3 - localized & 3 - localized & 3 - localized & 3 - localized \\
\hline & $d(\mathrm{Co}-\mathrm{O})$ & $\begin{array}{l}1.98 \times 2,1.97 \\
1.92 \times 2,1.91\end{array}$ & $\begin{array}{l}2.18 \times 2,2.14 \\
1.98,1.97 \times 2\end{array}$ & $\begin{array}{l}2.16 \times 2,2.13 \\
2.00,1.99,1.98\end{array}$ & $\begin{array}{l}2.14 \times 3,2.00 \times 2 \text {, } \\
1.98\end{array}$ & $\begin{array}{l}2.15,2.14,2.13 \\
2.00,1.99 \times 2\end{array}$ \\
\hline \multirow{2}{*}{$\mathrm{Mg}_{C o}-\mathrm{Li}_{i}$} & $d(\mathrm{Mg}-\mathrm{O})$ & $2.11 \times 3,1.98 \times 3$ & $2.11 \times 3,1.98 \times 3$ & $2.11 \times 3,1.98 \times 3$ & $2.11 \times 3,1.98 \times 3$ & $2.11 \times 3,1.98 \times 3$ \\
\hline & $d(\mathrm{Co}-\mathrm{O})$ & $\begin{array}{l}1.95,1.94 \times 2 \\
1.93 \times 2,1.92\end{array}$ & $\begin{array}{l}1.94 \times 3,1.93 \times 2, \\
1.92\end{array}$ & $\begin{array}{l}1.94 \times 3,1.93 \times 2, \\
1.92\end{array}$ & $\begin{array}{l}1.94 \times 3,1.93 \times 2 \\
1.92\end{array}$ & $\begin{array}{l}1.94 \times 3,1.93 \times 2, \\
1.92\end{array}$ \\
\hline \multirow[t]{2}{*}{$\mathrm{Mg}_{L i}-\mathrm{V}_{L i}$} & $d(\mathrm{Mg}-\mathrm{O})$ & $\begin{array}{l}2.12 \times 2,2.08 \times 2, \\
2.06 \times 2\end{array}$ & $\begin{array}{l}2.12 \times 2,2.08 \times 2, \\
2.06 \times 2\end{array}$ & $\begin{array}{l}2.12 \times 2,2.08 \times 2, \\
2.05 \times 2\end{array}$ & $\begin{array}{l}2.12 \times 2,2.08 \times 2, \\
2.05 \times 2\end{array}$ & $\begin{array}{l}2.12 \times 2,2.08 \times 2, \\
2.05 \times 2\end{array}$ \\
\hline & $d(\mathrm{Co}-\mathrm{O})$ & $\begin{array}{l}1.95 \times 2, \quad 1.94 \times 2 \\
1.92 \times 2\end{array}$ & $\begin{array}{l}1.95 \times 2, \quad 1.94 \times 2, \\
1.92 \times 2\end{array}$ & $\begin{array}{l}1.95 \times 2, \quad 1.94 \times 2, \\
1.92 \times 2\end{array}$ & $\begin{array}{l}1.95 \times 2,1.94 \times 2 \\
1.92 \times 2\end{array}$ & $\begin{array}{l}1.95 \times 2,1.94 \times 2 \\
1.92 \times 2\end{array}$ \\
\hline \multirow[t]{2}{*}{$\mathrm{Mg}_{C o}-\mathrm{Mg}_{L i}$} & $d\left(\mathrm{Mg}_{C o}-\mathrm{O}\right)$ & $\begin{array}{l}2.07 \times 2,2.04 \times 2 \\
2.02 \times 2\end{array}$ & $\begin{array}{l}2.07 \times 2,2.04 \times 2, \\
2.02 \times 2\end{array}$ & $\begin{array}{l}2.07 \times 2,2.04 \times 2, \\
2.02 \times 2\end{array}$ & $\begin{array}{l}2.07 \times 2,2.04 \times 2 \\
2.02 \times 2\end{array}$ & $\begin{array}{l}2.07 \times 2,2.04 \times 2, \\
2.01 \times 2\end{array}$ \\
\hline & $d\left(\mathrm{Mg}_{L i}-\mathrm{O}\right)$ & $2.10 \times 2,2.09$ & $2.10 \times 2,2.09$ & $\begin{array}{l}2.10 \times 2,2.09 \\
2.08\end{array}$ & $2.10 \times 2,2.09$ & $\begin{array}{l}2.10 \times 2,2.09 \\
2.08,206 \times 2\end{array}$ \\
\hline
\end{tabular}

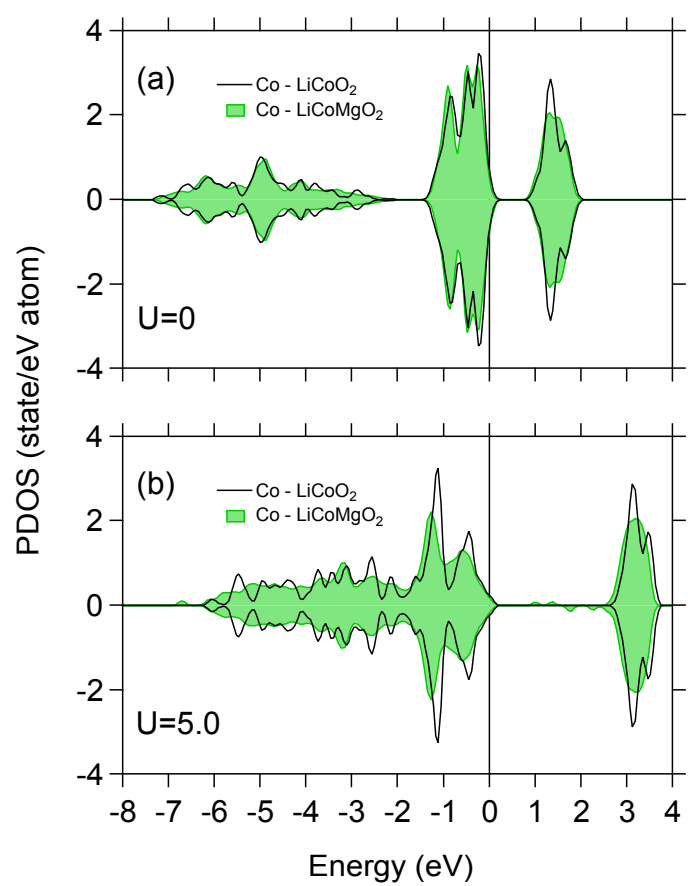

FIG. 5. Projected density of states (PDOS) of Co in $\mathrm{LiCoO}_{2}$ (solid curve) and $\mathrm{Mg}$-doped $\mathrm{LiCoO}_{2}$ (green colored area). Panels (a) and (b) correspond to GGA and GGA+U (U = $5.0 \mathrm{eV}$ ) calculations of the $\mathrm{Mg}_{C o}$ extrinsic defect. The energy is relative to the Valence Band Maximum (VBM).

sistent geometric properties.

\section{Electronic Structure}

$\mathrm{LiCoO}_{2}$ is a wide-band gap semiconductor. As found in previous calculations, $18,36,80,82-85$ GGA underestimates the band gap from the Valence Band Maximum (VBM) to the Conduction Band Minimum (CBM), i.e. $0.94 \mathrm{eV}$. The experimental values are $2.1, \underline{86} 2.5 \frac{87}{6}$ and $2.7 \mathrm{eV}: \underline{88}$ For GGA+U calculations, the predicted band gap depends on the $\mathrm{U}$ value. The band gap calculated with $\mathrm{U}$ $=3.3 \mathrm{eV}$ is $2.18 \mathrm{eV}$, in agreement with the experimental value of $2.1 \mathrm{eV}$ in Ref. 86, while the value of $\mathrm{U}=$ $5.0 \mathrm{eV}, 2.76 \mathrm{eV}$, reproduces the experimental value of $2.7 \mathrm{eV}$ in Ref. 88. These GGA+U results are similar to previous calculations with $\mathrm{U}$ values close to $3 \underline{80}$ and 5 $\mathrm{eV}, 51,55,80,83,89$

The electronic structure of $\mathrm{Mg}$-doped $\mathrm{LiCoO}_{2}$ was studied by calculating the electronic band structure and density of states (DOS) with GGA and GGA+U. Fig. 5 displays the projected DOS (PDOS) of Co in $\mathrm{LiCoO}_{2}$ and Mg-doped $\mathrm{LiCoO}_{2}$. The PDOS of Co in Fig. 5 (a) and (b) can be ascribed to three main groups $\underline{\underline{90}}$ The peaks from -7 to $-2 \mathrm{eV}$ corresponds to the occupied valence bands $\mathrm{e}_{g}{ }^{b}$, the group from -2 to $0.5 \mathrm{eV}$ to the partially occupied valence band $t_{2 g}$ and the peaks from 0.5 to $4 \mathrm{eV}$ to the unoccupied conduction band $\mathrm{e}_{g}{ }^{*} \underline{\underline{90}}$

The PDOS of $\mathrm{Co}$ in $\mathrm{Mg}$-doped $\mathrm{LiCoO}_{2}$ calculated with GGA, Fig. 5(a), is rather similar to that in pristine $\mathrm{LiCoO}_{2}$. Yet, some differences can be noticed. After Mgdoping, the PDOS in the energy range of the $\mathrm{e}_{g}{ }^{b}$ bands slightly increase while the PDOS in the region of the $\mathrm{t}_{2 g}$ bands decrease. In the region of the $\mathrm{e}_{g}{ }^{*}$ bands, the PDOS also decrease. These changes in the electron distribution upon doping with $\mathrm{Mg}$ indicate that $d$-electrons move from nonbonding bands to bonding bands $\frac{18}{16}$ The result is a higher valence state for $\mathrm{Co}$ in $\mathrm{Mg}$-doped $\mathrm{LiCoO}_{2}$ than in $\mathrm{LiCoO}_{2}$. In turn, the $\mathrm{O}$ anions become more closedshell like as indicated by the decrease of the PDOS in $\mathrm{e}_{g}{ }^{*}$ bands region, $\underline{18}$ The electron distribution also changes if $\mathrm{Mg}$ is located on a Li site instead of Co (data not shown). Moreover, these changes are also observed on the PDOS of Co calculated with GGA+U , Fig. 5(b). Therefore, both GGA and GGA+U calculations suggest that the valence of $\mathrm{Co}$ in $\mathrm{LiCoO}_{2}$ is modified when doping with 


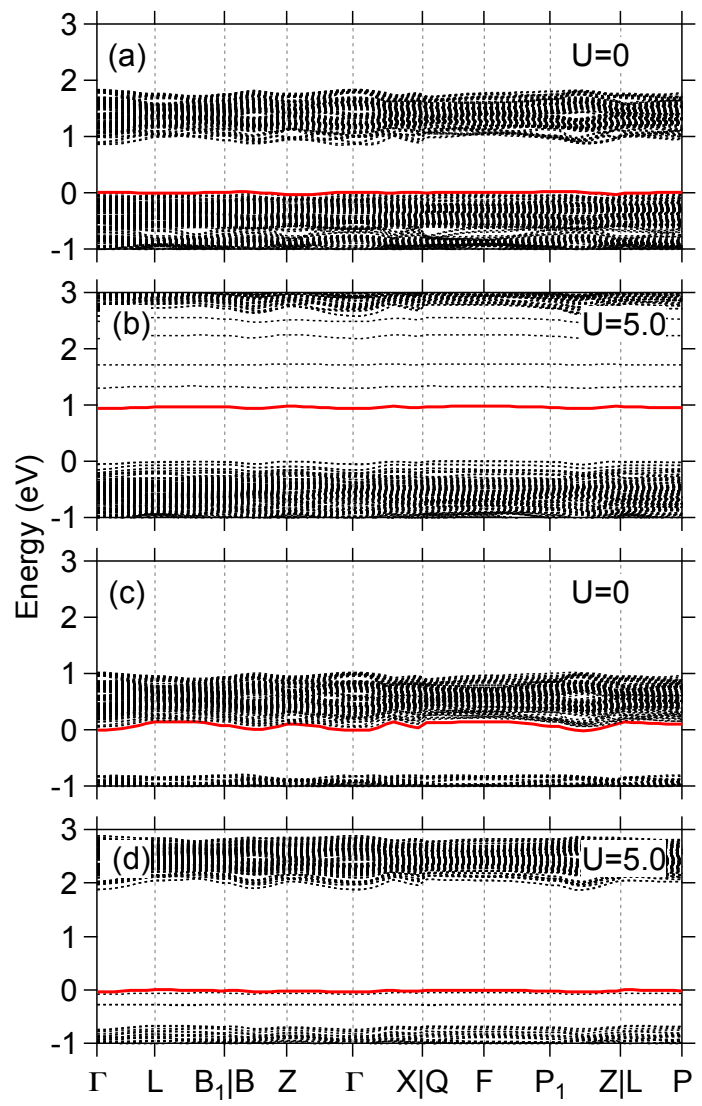

FIG. 6. Electronic band structures in the energy gap region of $\mathrm{LiCoO}_{2}$ with the $\mathrm{Mg}_{C o}$ (a and b) and $\mathrm{Mg}_{L i}$ defect (c and d) calculated with (a and c) GGA and (b and d) GGA+U with $\mathrm{U}=5.0$. The solid red curve indicates the impurity band. The energy is relative to the Valence Band Maximum (VBM). The high-symmetry directions of the rhombohedral Brillouin zone were generated with AFLOW ${ }^{91}$

$\mathrm{Mg}$.

As discussed previously, $\mathrm{Mg}_{C o}$ in $\mathrm{LiCoO}_{2}$ introduces an impurity hole in the system. This hole will be manifested in the band structure as an empty band close to the top of the valence band (shallow acceptor) or a band located "deep" in the band gap region. On the other hand, the formation of $\mathrm{Mg}_{L i}$ results in a electron that will lead to an occupied state close to the bottom of the conduction band (shallow donor) or an impurity state in the band gap region. In principle, both the shallow acceptor and shallow donor can increase the carrier density, leading to higher electronic conductivity. Conversely, no changes in electronic conductivity are expected if the impurity state is located in the band gap. Since Mg-doped $\mathrm{LiCoO}_{2}$ have been shown ${ }^{10.11}$ to have up to 2 orders of magnitude higher electronic conductivity than $\mathrm{LiCoO}_{2}$, one can expect either shallow acceptor or donor states in the band structure of $\mathrm{Mg}$-doped $\mathrm{LiCoO}_{2}$.

The electronic band structure near the valence and conduction bands of $\mathrm{LiCoO}_{2}$ with $\mathrm{Mg}_{C o}$ and $\mathrm{Mg}_{L i}$ is shown in Fig. 6. As expected, an empty band near the top of the valence band is predicted by GGA when $\mathrm{Mg}$ is located on Co, Fig. 6(a). Characteristic of a shallow acceptor level,,$\frac{57}{1}$ this level exhibits a similar dispersion as the upper valence band. A similar band structure is expected for $\mathrm{GGA}+\mathrm{U}$ calculations with $\mathrm{U}=1.5$ and $3.3 \mathrm{eV}$ since the geometry and spin-configuration of $\mathrm{Mg}_{C o}$ calculated with these methods are rather similar to those from GGA; this is confirmed by an increase in the density of states near the valence band maximum (data not shown). For GGA+U calculations with $\mathrm{U}=5.0 \mathrm{eV}$ or above, the impurity band associated with $\mathrm{Mg}_{C o}$ is located in the band gap region, Fig. 6(b). This level is spatially localized, leading to the local deformation observed for $\mathrm{Co}-\mathrm{O}$ and $\mathrm{Mg}-\mathrm{O}$ interatomic distances (Table III) and the splitting of unoccupied d-bands. When Mg is located on $\mathrm{Li}$, calculation with GGA shows an occupied band near the conduction band, Fig. 6(c). Notice that this band is now positioned at the Fermi level (or VBM). This shallow donor level exhibits dispersion similar to the bottom conduction band. As in $\mathrm{Mg}_{\mathrm{Co}}$, GGA+U leads to a localized impurity band when $\mathrm{Mg}_{L i}$ is formed, Fig. 6(d).

The energy position of the impurity levels in Mg-doped $\mathrm{LiCoO}_{2}$ are sensitive to the $\mathrm{U}$ value. For the $\mathrm{Mg}_{C o}$ defect, GGA and GGA+U calculations with $\mathrm{U}$ below 3.3 $\mathrm{eV}$ results on a shallow acceptor level, while calculations with $\mathrm{U}=5.0 \mathrm{eV}$ or higher leads to a localized level. The results of $\mathrm{U}=3.3 \mathrm{eV}$ or below explain the observed high electronic conductivity of $\mathrm{Mg}$-doped $\mathrm{LiCoO}_{2}$. However, these $\mathrm{U}$ values are not typically employed to study defects and impurities in $\mathrm{LiCoO}_{2}$ or similar materials. Instead, self-consistently determined $\frac{48}{} \mathrm{U}$ have been used $\stackrel{45,51}{ }$ For $\mathrm{Co}$, the self-consistent $\mathrm{U}$ values range from 4.91 to 5.62 $\mathrm{eV} \underline{\underline{48}}$ As our results show, $\mathrm{U}$ values in this range lead to deep levels in Mg-doped $\mathrm{LiCoO}_{2}$, which is inconsistent with the observed high electronic conductivity of this material.

\section{CONCLUSIONS}

In the present work, we have studied the doping of $\mathrm{LiCoO}_{2}$ with $\mathrm{Mg}$ employing the GGA and $\mathrm{GGA}+\mathrm{U}$ methods. In particular, we explored the effect of the $\mathrm{U}$ parameter on the energetic, geometric and electronic properties of $\mathrm{Mg}$ in $\mathrm{LiCoO}_{2}$. Our results show that these properties for $\mathrm{Mg}$ located on a $\mathrm{Co}$ or a $\mathrm{Li}$ site in $\mathrm{LiCoO}_{2}$ depend on the chosen $\mathrm{U}$ value. A similar dependence on $\mathrm{U}$ was also found in the properties of $\mathrm{Li}$ vacancy and $\mathrm{Li}$ interstitial defects in $\mathrm{LiCoO}_{2}$. The similarity arises because the substitutional $\mathrm{Mg}$ and the $\mathrm{Li}$ defects lead to impurity states in $\mathrm{LiCoO}_{2}$ with changes on the valency of $\mathrm{Co}$ in $\mathrm{LiCoO}_{2}$. The strong dependence on $\mathrm{U}$ of the energetic, geometric and electronic properties is a direct consequence of the valency change of Co. Increasing the $\mathrm{U}$ value eventually changes the impurity states from shallow to deep levels. Conversely, if $\mathrm{Mg}$ on Co or Li sites forms complexes and no impurity states are introduced in $\mathrm{LiCoO}_{2}$, the properties of such defect complexes are 
insensitive to the $\mathrm{U}$ value.

These results indicate that GGA/GGA+U methods may be used to study isovalent substitution in $\mathrm{LiCoO}_{2}$. For aliovalent substitution, such as $\mathrm{Mg}$ on a $\mathrm{Co}$ or a $\mathrm{Li}$ site, the usefulness of GGA/GGA+U methods is limited because experimental or theoretical data from accurate $a b$ initio methods $3,4,92-94$ are needed to validate the $\mathrm{U}$ dependent results. Moreover, even if such data were available, one is left with the problem of a single $U$ value not giving a reasonable overall description of the properties of $\mathrm{LiCoO}_{2}$. For example, $\mathrm{U}$ values close to $3^{80}$ and 5 51,80,83,89 $\mathrm{eV}$ result in band gaps similar to experimental values, $\mathrm{U}=3.3^{50} \mathrm{eV}$ correctly describes some of the major features in the phase diagram of $\mathrm{LiCoO}_{2}$ while $\mathrm{U}$ values close to $5 \underline{48,71} \mathrm{eV}$ are needed to reproduce the measured average Li-intercalation potential. Our present results show that $\mathrm{U}$ values of $3.3 \mathrm{eV}$ and lower can describe the high electronic conductivity of $\mathrm{Mg}$-doped $\mathrm{LiCoO}_{2}$ but $\mathrm{U}$ as low as $1.5 \mathrm{eV}$ are needed to describe the solubility of $\mathrm{Mg}$ in $\mathrm{LiCoO}_{2}$. Finally, even if a perfect $\mathrm{U}$ value could be found, it would not improve the oxygen molecule formation energy or the thermodynamic properties of materials without d electrons. Empirical corrections would still be required.

\section{ACKNOWLEDGMENTS}

The work was supported by the Materials Sciences \& Engineering Division of the Office of Basic Energy Sciences, U.S. Department of Energy (DOE). Research by PRCK was conducted at the Center for Nanophase Materials Sciences, which is sponsored at Oak Ridge National Laboratory by the Scientific User Facilities Division, Office of Basic Energy Sciences, U.S. Department of Energy.

${ }^{1}$ G. Ceder, G. Hautier, A. Jain, and S. Ong, MRS Bulletin 36, 185 (2011).

${ }^{2}$ J. Kolorenč and L. Mitas, Rep. Prog. Phys. 74, 026502 (2011).

${ }^{3}$ G. H. Booth, A. Grüneis, G. Kresse, and A. Alavi, Nature 493, 365 (2013)

${ }^{4} \mathrm{~L}$ Shulenburger and T. R. Mattsson, Phys. Rev. B 88, 245117 (2013)

5 "Materials genome initiative for global competitiveness," http://www.whitehouse.gov/mgi (2014).

${ }^{6}$ C. Wolverton and A. Zunger, Phys. Rev. Lett. 81, 606 (1998)

${ }^{7}$ A. Van der Ven, M. K. Aydinol, G. Ceder, G. Kresse, and J. Hafner, Phys. Rev. B 58, 2975 (1998)

${ }^{8}$ C. A. Marianetti, G. Kotliar, and G. Ceder,

Nat. Mater. 3, 627 (2004)

${ }^{9}$ J. P. Perdew and A. Zunger, Phys. Rev. B 23, 5048 (1981)

${ }^{10}$ M. Carewska, S. Scaccia, F. Croce, S. Arumugam, Y. Wang, and S. Greenbaum, Solid State Ionics 93, 227 (1997)

${ }^{11} \mathrm{H}$. Tukamoto and A. R. West, J. Electrochem. Soc. 144, 3164 (1997)

${ }^{12}$ C. Julien, M. Camacho-Lopez, T. Mohan, S. Chitra, P. Kalyani, and S. Gopukumar, Solid State Ionics 135, 241 (2000)

${ }^{13}$ M. Mladenov, R. Stoyanova, E. Zhecheva, and S. Vassilev, Electrochem. Commun. 3, 410 (2001)

${ }^{14}$ R. Stoyanova, E. Zhecheva, M. I. Mladenov, P. Zlatilova, and S. Vassilev (Springer Netherlands, Dordrecht, 2002) pp. 463-468. ${ }^{15} \mathrm{~S}$. Levasseur, M. Ménétrier, and C. Delmas, Chem. Mater. 14, 3584 (2002)
${ }^{16}$ S. Madhavi, G. Subba Rao, B. Chowdari, and S. Li, Solid State Ionics 152153, 199 (2002)

${ }^{17} \mathrm{G}$. Chen, C. Li, X. Xu, J. Li, and U. Kolb, Appl. Phys. Lett. 83, 1142 (2003)

${ }^{18}$ X. G. Xu, C. Li, J. X. Li, U. Kolb, F. Wu, and G. Chen, J. Phys. Chem. B 107, 11648 (2003)

${ }^{19}$ S. Frangini, $\quad$ S. Scaccia,

Electrochim. Acta 48, 3473 (2003)

${ }^{20}$ C. Li, X. Xu, C. Wang, Y. Xu, W. Xu, and G. Chen, J. Mater. Sci. Lett. 22, 1183 (2003)

${ }^{21}$ P. Elumalai, H. Vasan, and N. Munichandraiah, J. Power Sources 125, 77 (2004)

${ }^{22}$ H.-S. Kim, T.-K. Ko, B.-K. Na, W. I. Cho, and B. W. Chao, J. Power Sources 138, 232 (2004)

${ }^{23}$ F. Nobili, S. Dsoke, F. Croce, and R. Marassi, Electrochim. Acta 50, 2307 (2005)

${ }^{24} \mathrm{H} . \quad \mathrm{Xu}, \quad \mathrm{S} . \mathrm{Xie}, \mathrm{C}$ Zhang, and C. Chen, J. Power Sources 148, 90 (2005)

${ }^{25}$ H.-J. Kim, Y. U. Jeong, J.-H. Lee, and J.-J. Kim, J. Power Sources 159, 233 (2006)

${ }^{26}$ R. Sathiyamoorthi, P. Shakkthivel, R. Gangadharan, and T. Vasudevan, Ionics 13, 25 (2007).

${ }^{27}$ J. Eom and J. Cho, J. Electrochem. Soc. 155, A201 (2008)

${ }^{28}$ C. Zaheena, C. Nithya, R. Thirunakaran, A. Sivashanmugam, and S. Gopukumar, Electrochim. Acta 54, 2877 (2009)

${ }^{29}$ F. Zhou, W. Luo, X. Zhao, and J. R. Dahn, J. Electrochem. Soc. 156, A917 (2009).

${ }^{30} \mathrm{~W}$. Luo, X. Li, and J. R. Dahn, J. Electrochem. Soc. 157, A782 (2010)

${ }^{31} \mathrm{~S}$. Valanarasu, R. Chandramohan, J. Thirumalai, T. A. Vijayan, S. R. Srikumar, and T. Mahalingam, J Mater Sci: Mater Electron 21, 827 (2010)

${ }^{32}$ H.-G. Jung, N. V. Gopal, J. Prakash, D.-W. Kim, and Y.-K. Sun, Electrochim. Acta 68, 153 (2012)

${ }^{33}$ F. Nobili, F. Croce, R. Tossici, I. Meschini, P. Reale, and R. Marassi, J. Power Sources 197, 276 (2012).

${ }^{34}$ X. G. Xu, Y. J. Wei, X. Meng, C. Z. Wang, Z. F. Huang, and G. Chen, Acta Phys. Sin. 53, 210 (2004).

${ }^{35}$ X. G. Xu, C. Z. Wang, W. Lu, X. Meng, Y. Sun, and G. Chen, Acta Phys. Sin. 54, 313 (2005).

${ }^{36} \mathrm{~S}$. Shi, C. Ouyang, M. Lei, and W. Tang, J. Power Sources 171, 908 (2007)

${ }^{37}$ C.-C. Chang, J. Y. Kim, and P. N. Kumta, J. Electrochem. Soc. 147, 1722 (2000)

${ }^{38}$ J. Cho, Chem. Mater. 12, 3089 (2000)

${ }^{39}$ H.-J. Kweon, S. J. Kim, and D. G. Park, J. Power Sources 88, 255 (2000)

${ }^{40} \mathrm{~J}$. Cho, G. Kim, and H. S. Lim, J. Electrochem. Soc. 146, 3571 (1999)

${ }^{41}$ C. Pouillerie, L. Croguennec, P. Biensan, P. Willmann, and C. Delmas, J. Electrochem. Soc. 147, 2061 (2000).

${ }^{42}$ C. Pouillerie, F. Perton, P. Biensan, J. Prs, M. Broussely, and C. Delmas, J. Power Sources 96, 293 (2001)

${ }^{43}$ A. D'Epifanio, F. Croce, F. Ronci, V. Rossi Albertini, E. Traversa, and B. Scrosati, Chem. Mater. 16, 3559 (2004)

${ }^{44}$ J. Xiang, C. Chang, F. Zhang, and J. Sun, J. Electrochem. Soc. 155, A520 (2008)

${ }^{45}$ K. Tatsumi, Y. Sasano, S. Muto, T. Yoshida, T. Sasaki, K. Horibuchi, Y. Takeuchi, and Y. Ukyo, Phys. Rev. B 78, 045108 (2008)

${ }^{46}$ A. H. Tavakoli, H. Kondo, Y. Ukyo, and A. Navrotsky, J. Electrochem. Soc. 160, A302 (2013).

${ }^{47}$ V. I. Anisimov, F. Aryasetiawan, and A. I. Lichtenstein, J. Phys.: Condens. Matter 9, 767 (1997)

${ }^{48}$ F. Zhou, M. Cococcioni, C. A. Marianetti, D. Morgan, and G. Ceder, Phys. Rev. B 70, 235121 (2004)

${ }^{49}$ L. Wang, T. Maxisch, and G. Ceder, Chem. Mater. 19, 543 (2007)

${ }^{50}$ D. Kramer and G. Ceder, Chem. Mater. 21, 3799 (2009)

${ }^{51}$ Y. Koyama, H. Arai, I. Tanaka, Y. Uchimoto, and Z. Ogumi, 
Chem. Mater. 24, 3886 (2012)

${ }^{52} \mathrm{~L}$ Wang, T. Maxisch, and G. Ceder, Phys. Rev. B 73, 195107 (2006)

${ }^{53}$ A. Jain, G. Hautier, S. P. Ong, C. J. Moore, C. C. Fischer, K. A. Persson, and G. Ceder, Phys. Rev. B 84, 045115 (2011)

${ }^{54}$ A. Jain, S. P. Ong, G. Hautier, W. Chen, W. D. Richards, S. Dacek, S. Cholia, D. Gunter, D. Skinner, G. Ceder, and K. A. Persson, APL Materials 1, 011002 (2013)

${ }^{55} \mathrm{~K}$. Hoang and M. D. Johannes, J. Mater. Chem. A 2, 5224 (2014)

${ }^{56}$ Calculations performed with GGA $+\mathrm{U}=5.5 \mathrm{eV}$.

${ }^{57}$ C. G. Van de Walle and J. Neugebauer, J. Appl. Phys. 95, 3851 (2004).

${ }^{58}$ G. Kresse and J. Hafner, Phys. Rev. B 47, 558 (1993)

${ }^{59}$ G. Kresse and J. Hafner, Phys. Rev. B 49, 14251 (1994)

${ }^{60}$ G. Kresse and J. Furthmüller, Comp. Mater. Sci. 6, 15 (1996)

${ }^{61}$ G. Kresse and J. Furthmüller, Phys. Rev. B 54, 11169 (1996)

${ }^{62}$ J. P. Perdew, K. Burke, and M. Ernzerhof, Phys. Rev. Lett. 77, 3865 (1996)

${ }^{63}$ J. P. Perdew, K. Burke, and M. Ernzerhof, Phys. Rev. Lett. 78, 1396 (1997)

${ }^{64}$ P. E. Blöchl, Phys. Rev. B 50, 17953 (1994)

${ }^{65}$ G. Kresse and D. Joubert, Phys. Rev. B 59, 1758 (1999)

${ }^{66} \mathrm{~K}$. Momma and F. Izumi, J. Appl. Crystallogr. 41, 653658 (2008)

${ }^{67}$ S. Grindy, B. Meredig, S. Kirklin, J. E. Saal, and C. Wolverton, Phys. Rev. B 87, 075150 (2013)

${ }^{68}$ A. Jain, G. Hautier, C. J. Moore, S. Ping Ong, C. C. Fischer, T. Mueller, K. A. Persson, and G. Ceder, Comp. Mater. Sci. 50, 2295 (2011)

${ }^{69}$ W. M. Haynes, CRC Handbook of Chemistry and Physics, 94th edition (Taylor \& Francis Limited, 2013).

${ }^{70}$ S. L. Dudarev, G. A. Botton, S. Y. Savrasov, C. J. Humphreys, and A. P. Sutton, Phys. Rev. B 57, 1505 (1998)

${ }^{71}$ V. L. Chevrier, S. P. Ong, R. Armiento, M. K. Y. Chan, and G. Ceder, Phys. Rev. B 82, 075122 (2010)

${ }^{72}$ V. Stevanović, S. Lany, X. Zhang, and A. Zunger, Phys. Rev. B 85, 115104 (2012)

${ }^{73}$ S. P. Ong, L. Wang, B. Kang, and G. Ceder, Chem. Mater. 20, 1798 (2008)

${ }^{74}$ A. Jain, G. Hautier, S. Ong, C. Moore, C. Fischer, K. Persson, and G. Ceder, Phys. Rev. B 84, 045115 (2011)
${ }^{75}$ https://materialsproject.org/\#apps/phasediagram (2014).

${ }^{76}$ S.-H. Wei, Comp. Mater. Sci. 30, 337 (2004)

${ }^{77}$ H. Dixit, N. Tandon, S. Cottenier, R. Saniz, D. Lamoen, and B. Partoens, Phys. Rev. B 87, 174101 (2013)

${ }^{78} \mathrm{M}$. Wang and A. Navrotsky, J. Solid State Chem. 178, 1230 (2005)

${ }^{79} \mathrm{M}$. W. Chase and National Institute of Standards and Technology (U.S.), (American Chemical Society ; American Institute of Physics for the National Institute of Standards and Technology, [Washington, D.C.]; Woodbury, N.Y., 1998).

${ }^{80}$ D. Ensling, A. Thissen, S. Laubach, P. C. Schmidt, and W. Jaegermann, Phys. Rev. B 82, 195431 (2010)

${ }^{81}$ R. Thirunakaran, N. Kalaiselvi, P. Periasamy, and N. G. Renganathan, Ionics 9, 388 (2003)

${ }^{82}$ M. T. Czyyk, R. Potze, and G. A. Sawatzky, Phys. Rev. B 46, 3729 (1992)

${ }^{83}$ A. Juhin, F. de Groot, G. Vank, M. Calandra, and C. Brouder, Phys. Rev. B 81, 115115 (2010)

${ }^{84}$ Z. H. Sun, W. H. Liu, Q. X. Wan, D. M. Li, and Z. H. Xiong, Adv. Mat. Res. 415-417, 1643 (2011).

${ }^{85}$ T. Okumura, Y. Yamaguchi, M. Shikano, and H. Kobayashi, J. Mater. Chem. 22, 17340 (2012)

${ }^{86} \mathrm{~K}$. Kushida and

Solid State Commun. 123, 349 (2002)

${ }^{87}$ J. Rosolen and F. Decker, J. Electroanal. Chem. 501, 253 (2001)

${ }^{88} \mathrm{~J}$. van Elp, J. L. Wieland, H. Eskes, P. Kuiper, G. A. Sawatzky, F. M. F. de Groot, and T. S. Turner, Phys. Rev. B 44, 6090 (1991)

${ }^{89}$ F. Xiong, H. J. Yan, Y. Chen, B. Xu, J. X. Le, and C. Y. Ouyang, Int. J. Electrochem. Sci. 7, 9390 (2012).

${ }^{90}$ M. K. Aydinol, A. F. Kohan, G. Ceder, K. Cho, and J. Joannopoulos, Phys. Rev. B 56, 1354 (1997)

${ }^{91} \mathrm{~W}$ Setyawan and S. Curtarolo, Comp. Mater. Sci. 49, 299 (2010)

${ }^{92}$ L. K. Wagner, Int. J. Quantum Chem 114, 94101 (2014)

${ }^{93} \mathrm{~L}$ K. Wagner and P. Abbamonte, arXiv:1402.4680 [cond-mat] (2014)

${ }^{94}$ K. Foyevtsova, J. T. Krogel, J. Kim, P. R. C. Kent, E. Dagotto, and F. A. Reboredo, arXiv preprint arXiv:1402.5561 (2014) 